\title{
Reconstrução paleoambiental da Laguna de Maricá, RJ, com base em foraminíferos bentônicos
}

\author{
Regina L. M. BRUNO
}

Departamento de Paleontologia e Estratigrafia, Universidade Federal do Rio de Janeiro. Av. Athos da Silveira Ramos, 274, bloco G, Cidade Universitária, Ilha do Fundão, CEP 21.941-916, Rio de Janeiro, RJ, Brasil. E-mail: regina_forams@yahoo.com.br.

Recebido em 08/2012. Aceito para publicação em 10/2013.

Versão online publicada em 02/12/2013 (www.pesquisasemgeociencias.ufrgs.br)

\begin{abstract}
Resumo - Com o objetivo de avaliar a evolução costeira baseada na distribuição dos foraminíferos bentônicos e nos aspectos sedimentológicos, duas testemunhagens foram realizadas na Laguna de Maricá, Rio de Janeiro. Duas biofácies foram reconhecidas: (i) biofácies Ap-At (Ammonia parkinsoniana - A tepida) correspondendo à metade inferior de ambos os testemunhos, -caracterizada pela abundância de foraminíferos calcário-hialinos, entre os quais destacam-se Ammonia parkinsoniana e A. tepida, associada à intercalação de lama siltosa e lama arenosa com conchas desgastadas e quebradas, sugerindo eventos de ondas de tempestades; e (ii) biofácies Ac-As (Ammotium cassis - A. salsum) compreendendo à metade superior dos testemunhos, caracterizada por espécies aglutinantes, como Ammotium cassis, A. salsum, Trochammina inflata, Miliammina fusca e Ammobaculites spp., associados à lama siltosa e à ocorrência de alguns micromoluscos, indicando uma fase de baixa energia hidrodinâmica. Este registro da distribuição de foraminíferos calcários e aglutinantes relaciona-se principalmente com a dinâmica de abertura e fechamento da barreira arenosa da Laguna de Maricá.
\end{abstract}

Palavras-chave: foraminíferos, laguna, paleoambiente, evolução costeira.

Abstract - PAleoenvironmental Reconstruction of the MARicá LAgoon, RJ, BASEd on BENTHiC ForaminiFERA. In order to evaluate the coastal evolution based on the distribution of benthic foraminifera associated with sedimentological features, two cores were drilled at the Maricá Lagoon, Rio de Janeiro. Two biofacies were recognized: (i) Ap-At (Ammonia parkinsoniana - A. tepida) biofacies - corresponding to the lower portion of the cores, -characterized by abundance of calcareous-hyaline foraminifera, such as Ammonia parkinsoniana and A. tepida, associated with the intercalation of silty mud and sandy mud with abrasion and broken shells, suggesting storm wave events; and (ii) Ac-As (Ammotium cassis - A. salsum) biofacies - comprising the upper portion of the cores, characterized by agglutinated species, such as Ammotium cassis, A. salsum, Trochammina inflata, Miliammina fusca, Ammobaculites spp., associated with silty mud and occurrence of microshells, indicating a low energy environment. This record of calcareous and hyaline foraminifera distribution is mainly related with the dynamic opening and closing of the sandy barriers Maricá Lagoon.

Keywords: foraminifera, lagoon, paleoenvironment, coastal evolution.

\section{Introdução}

A costa leste fluminense é composta por inúmeras lagunas e sistemas lagunares associados, os quais representam importantes habitats para uma ampla variedade de organismos, incluindo foraminíferos bentônicos, diatomáceas, vermetídeos, bivalves, entre outros. Além disso, essas lagunas apresentam peculiaridades quanto ao seu processo de formação, uma vez que derivam de antigas baías que foram fechadas pela formação e migração de cordões arenosos (Martin et al., 1996; Martin et al., 2003; Laslandes et al., 2006; Dias et al., 2009). Este processo relaciona-se às oscilações do nível do mar ocorridas no Pleistoceno e Holoceno, incluindo eventos de ondas de tempestades (Kjerfve, 1994), sendo responsável também pela ampla distribuição dos foraminíferos nas lagunas.

A distribuição dos foraminíferos bentônicos nas lagunas está associada aos diversos parâmetros abióticos, dentre os quais se destacam: a disponibilidade de alimentos seja por simbiose com algas ou através da concentração da matéria orgânica (Jorissen, 1999); nível de oxigenação (Murray, 2006); salinidade (Horton \& Murray, 2007); presença de minerais para a construção das tecas (Boltovskoy, 1965); hidrodinâmica do ambiente (Massey et al., 2006); pH para a seleção de assembleias calcárias e aglutinantes (Murray \& Alve, 1999), entre outros.

A distribuição quantitativa dos foraminíferos bentônicos em testemunhos quando comparados aos fatores abióticos podem indicar estágios de evolução e mudanças geomorfológicas locais, contribuindo assim, para a reconstrução de paleoambientes (Vance et al., 2006; Cearreta et al., 2007; Blázquez \& Usera, 2010). Os foraminíferos têm sido amplamente empregados para estudos em ambientes restritos (baías, lagunas e 
estuários), uma vez que suas sensibilidades às alterações ambientais permite a compreensão mais precisa das modificações do meio, além de informar paleonível costeiro (Leorri \& Cearreta, 2004; Woodroffe et al., 2005).

Os trabalhos realizados com base em foraminíferos de ambientes lagunares visam detectar: (i) impacto ambiental, seja ocasionado por ação antrópica ou por alterações naturais (Frontalini et al., 2009) e (ii) reconstrução paleoambiental através da análise biofaciológica em testemunhos que permite uma interpretação relacionada à evolução do arcabouço sedimentar lagunar (Bruno, 2012). 0 presente trabalho visa avaliar a assembleia de foraminíferos associada às fácies sedimentares registradas em dois testemunhos na Laguna de Maricá, Rio de Janeiro, a fim de realizar uma reconstrução paleoambiental e microfaunística.

\section{2 Área de estudo}

A Laguna de Maricá faz parte do complexo lagunar Maricá-Guarapina, que dista cerca de $60 \mathrm{~km}$ da cidade do Rio de Janeiro e ocupa uma área de $38 \mathrm{~km}^{2}$, sendo composto pelas lagunas de Maricá $\left(19,5 \mathrm{~km}^{2}\right)$, Barra $\left(9,0 \mathrm{~km}^{2}\right)$, Padre $\left(3,0 \mathrm{~km}^{2}\right)$ e Guarapina $\left(6,5 \mathrm{~km}^{2}\right)$, incluindo dois canais artificiais, São Bento e Ponta Negra (Fig. 1) (FEEMA, 1995). As margens internas deste sistema revelam, em seu delineamento irregular, um antigo litoral recortado, com promontórios de rochas cristalinas que avançam para o mar (Lamego, 1945).

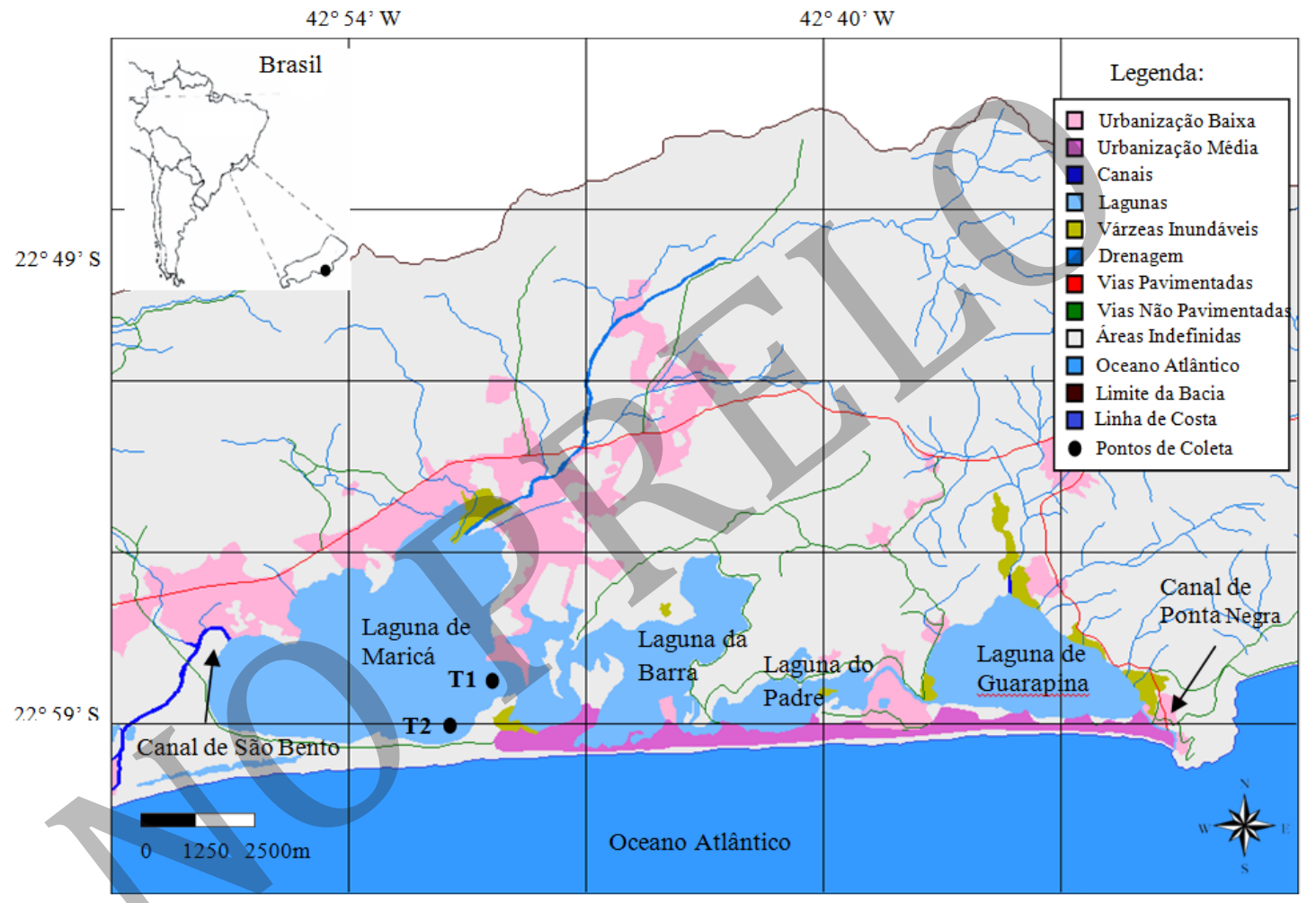

Figura 1. Área de estudo, com os pontos de coleta (T1 e T2) na Laguna de Maricá, RJ.

Segundo Muehe (1984), Perrin (1999) e Turcq et al. (1999) os cordões litorâneos e lagunas associadas à área de Maricá formaram-se por ocasião da transgressão holocênica (7000-5000 anos AP), apresentando caráter progradacional. Em outros trechos próximos a presente área, ocorreu dois cordões paralelos, um mais interno e mais antigo, e o outro mais recente associado à praia atual. A formação da primeira barreira arenosa da Laguna de Maricá ocorreu durante o Pleistoceno, enquanto a segunda barreira arenosa se formou durante o Holoceno. Esta última originou uma planície lagunar composta por duplos cordões e lagunas intracordões associadas (Fig. 2). Segundo Silva et al. (2010) o sistema barreira-laguna de Maricá, apresenta cinco unidades deposicionais repousando sobre o embasamento Pré-Cambriano, com espessura total superior a 20 m. A barreira arenosa interna da Laguna de Maricá apresenta descontinuidades, com avanço sobre a ca- mada de lama lagunar pleistocênica, indicando possivelmente uma transgressão e sua idade corresponde a $40880 \pm 1420$ anos AP.

Flexor et al. (1984) pesquisaram a ocorrência das planícies quaternárias no litoral brasileiro, incluindo a costa do Rio de Janeiro. No trabalho, os autores documentaram a origem e formação dos cordões litorâneos, como consequência do rebaixamento do nível médio relativo do mar e aporte de areia proveniente da plataforma proximal. A presença de esporões arenosos ao longo da margem intracordões é facilmente reconhecida no litoral da Laguna de Maricá. Segundo Davis \& Kuhn (1985) e Carter (1988) os leques de arrombamento constituem importantes componentes do registro estratigráfico costeiro, pois perfazem porcentagens significativas de depósitos de ilhas-barreiras e barreiras arenosas, sendo relevantes na compreensão da dinâmica costeira. Os leques de arrombamento 


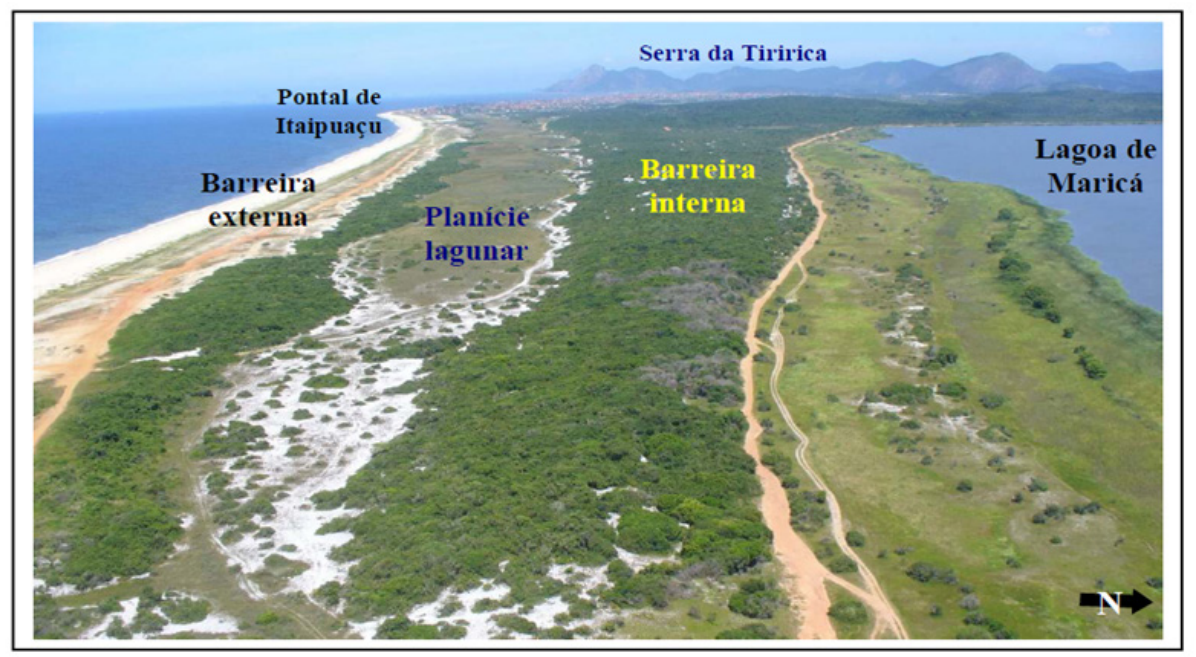

Figura 2. Principais elementos geomórficos do sistema laguna-barreira de Maricá (Foto: Desirée Guichar; Silva \& Silva, 2010).

originam-se a partir de ondas de ressaca, geradas por eventos de tempestade em direção ao continente e resultam da acumulação sedimentar transportada pelo mar próximo à praia em direção à porção interna da barreira arenosa ou sentido pós-praia (Labuz, 2009). 0 alcance e/ou extensão do leque de arrombamento e as respostas na morfologia da barreira dependem da interação de determinadas variáveis, como: (i) intensidade, alcance e duração das ondas de tempestades; (ii) ação construtiva e destrutiva das ondas de tempestades; (iii) diferença de nível d'água entre oceano e laguna e variações do nível do mar (Morton \& Sallenger, 2003).

Durante o último evento transgressivo, os cursos fluviais foram afogados e transformados em desembocaduras de estuários; posteriormente, formaram-se as ilhas-barreiras que isolaram alguns sistemas de lagunas (Suguio et al., 1985). Segundo Martin et al. (1996) durante o período de submersão (aumento relativo do nível do mar), as ilhas-barreiras e sistemas lagunares foram dominantes possibilitando a construção de deltas. Em contraste, a queda do nível do mar, favoreceu a emersão de lagunas e baías, e planícies de cristas de praia que rapidamente progradaram, resultando em uma camada de areia regressiva.

O clima da região de Maricá é classificado como tropical quente, superúmido, com subseca, sendo a temperatura média anual de $23,2^{\circ} \mathrm{C}$. A média das máximas do mês mais quente (fevereiro) é $32,2^{\circ} \mathrm{C}$ e das mínimas do mês mais frio (julho) é $15,1^{\circ} \mathrm{C}$, sendo a precipitação média anual de 1.230,8 mm (Nimer, 1979; Barbiére \& Coe Neto, 1999). A salinidade do fundo e da superfície mensurada na Laguna de Maricá apresentam valores entre 7-8 e $5 \%$, respectivamente, sendo classificada como laguna hipossalina, segundo Miranda et al. (2002).

\section{Materiais e métodos}

Duas testemunhagens foram realizadas na Laguna de Maricá, Rio de Janeiro, em áreas próximas à linha de costa, a fim de analisar interpretações relacionadas aos processos costeiros. 0 primeiro testemunho (T1/MAR, $22^{\circ} 56^{\prime} \mathrm{S} / 42^{\circ} 49^{\prime} \mathrm{W}$ ) possui $178 \mathrm{~cm}$ de comprimento e o segundo testemunho (T2/MAR, 22 $2^{\circ} 57^{\prime} \mathrm{S} / 42^{\circ} 50^{\prime} \mathrm{W}$ ) $168 \mathrm{~cm}$ (Fig. 1).

Os testemunhos foram descritos segundo o padrão de coloração, composição e conteúdo bioclástico (níveis de fragmentos de conchas). Posteriormente, foram amostrados a cada $10 \mathrm{~cm}$, com alíquota de $2 \mathrm{~cm}$ por amostra e padronizados em $30 \mathrm{ml}$, para a lavagem na peneira com malha de $0,062 \mathrm{~mm}$ de abertura.

A partir da amostra seca, foi triado um mínimo de 100 indivíduos, para a análise e identificação taxonômica, com base em bibliografia especializada. Segundo Patterson \& Fishbein (1989) a contabilização mínima de 100 indivíduos triados por amostra representa uma acurácia suficiente para identificar maiores diferenças na abundância relativa das espécies. Fatela \& Taborba (2002) relatam que a triagem de 100 foraminíferos por amostra constitui de forma satisfatória uma confiabilidade estatística. Desta forma, a contabilização de 100 foraminíferos é aplicada em ambientes restritos como baías, lagunas e estuários, devido a estes ambientes apresentarem baixa diversidade.

Para os dados de Carbono Orgânico Total (COT), foram selecionadas amostras com texturas e colorações diferentes, sendo realizadas análises por combustão através do analisador LECO SC-144DR.

A datação por ${ }^{14} \mathrm{C}$ em conchas e fragmentos bioclásticos foi realizada pelo Laboratório Beta Analytic Inc. (Flórida) pelo método de quantificação da emissão de radiocarbono por acelerador de espectrometria de massa (AMS). 0 testemunho T1 foi datado e correlacionado ao T2, sendo calibrado de acordo com a metodologia de Stuiver \& Reimer (1993), nos intervalos de 177-175 cm (2740-2460 cal anos AP), em 96-94 cm (1040-970 cal anos AP) e em 50-48 cm (460-350 cal anos AP). 


\section{Resultados}

\subsection{Composição sedimentológica}

A composição sedimentológica registrada nos testemunhos da Laguna de Maricá consiste basicamente na intercalação de lama siltosa e lama arenosa, com coloração de cinza-médio a cinza-escuro contendo conchas desgastadas e fragmentadas.

Em relação à correlação dos testemunhos, o primeiro registro de alta energia hidrodinâmica (Fig. 3) do testemunho T1 data aproximadamente 2740-2460 cal anos AP (177-175 cm), correspondendo ao intervalo de 178-155 cm, sendo correlacionado ao intervalo entre 168-160 cm no T2. Esta camada é composta de lama arenosa, com uma concentração de conchas desarticuladas e fragmentadas. De $154-146 \mathrm{~cm}$ no T1 e
159-150 cm no T2, observou-se o registro de lama siltosa, sugerindo condição de baixa energia hidrodinâmica.

O segundo registro de alta energia hidrodinâmica (Fig. 3), marcado pela presença de fragmentos de conchas no intervalo de $145-142 \mathrm{~cm}$ no T1, foi correlacionado ao intervalo de $149-141 \mathrm{~cm}$ no T2. 0 intervalo entre $141-126 \mathrm{~cm}$ no T1 foi correlacionado ao intervalo entre 140-122 cm no T2, composto predominantemente por lama siltosa, indicando fase de baixa energia.

0 terceiro nível de alta energia hidrodinâmica (Fig. 3) compreendido nas profundidades de 125-122 cm no T1 foi correlacionado ao intervalo de 121-114 cm no T2, onde há uma concentração de fragmentos de conchas. A seguinte fase de baixa energia é representada por um nível de lama siltosa com laminações biodetríticas, entre $121-105 \mathrm{~cm}$ no T1 foi correlacionado ao nível entre 113-100 cm de lama siltosa no T2.

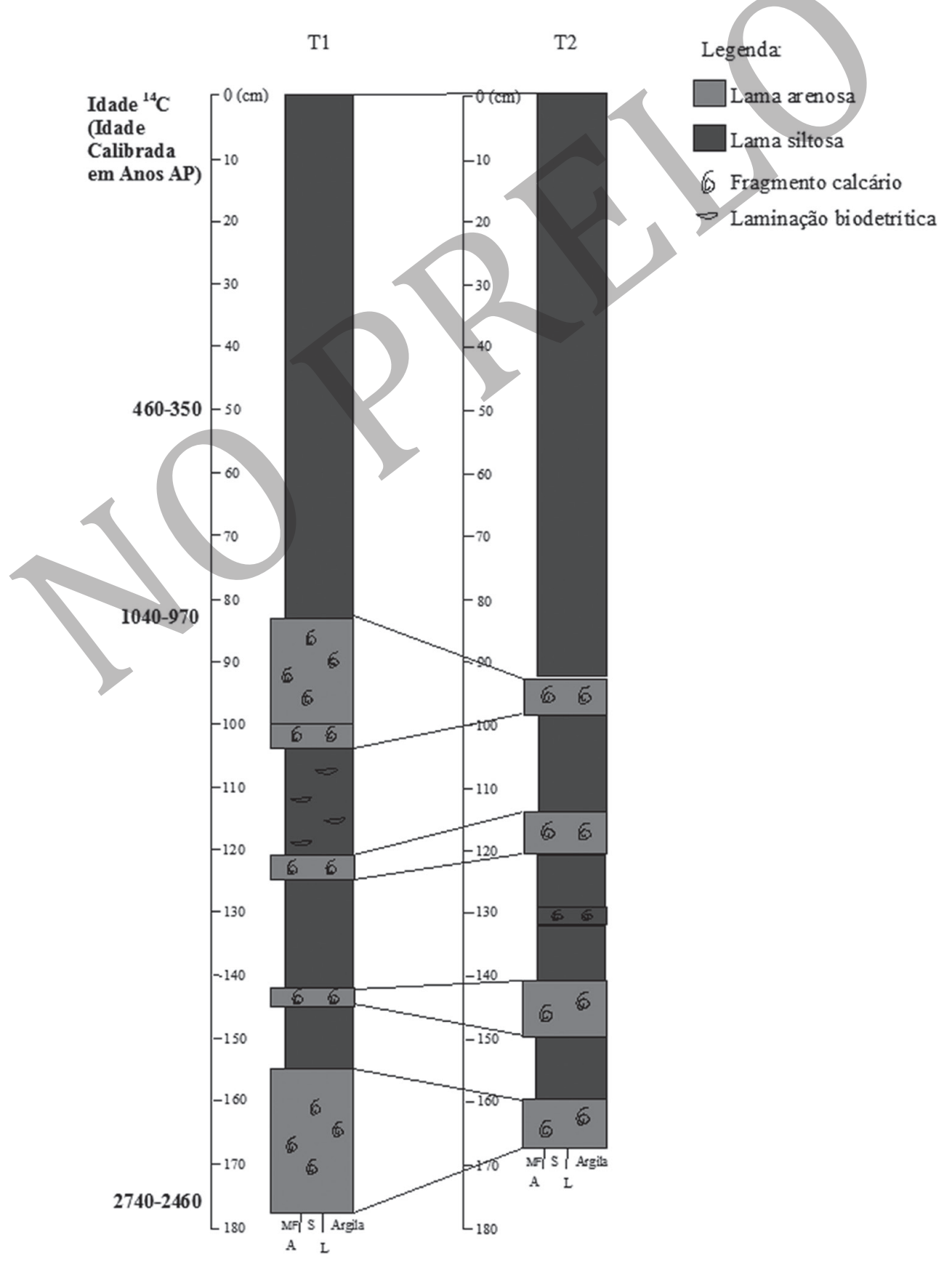

Figura 3. Correlação dos testemunhos T1 e T2 da Laguna de Maricá. 
O último registro de alta energia hidrodinâmica na Laguna de Maricá (Fig. 3) data há aproximadamente 1040-970 cal anos AP (96-94 cm) e corresponde ao intervalo de 104-83 cm no T1, tendo sido correlacionado ao intervalo de 99-93 cm no T2, o qual se compõe de lama arenosa com fragmentos bioclásticos. 0 intervalo compreendido entre $82 \mathrm{~cm}$ ao topo do T1 e de $92 \mathrm{~cm}$ ao topo do T2, é composto por lama siltosa, com discretas laminações biodetríticas, correspondendo à fase final de baixa energia de deposição lagunar.

\subsection{Assembleias de foraminíferos}

As associações de foraminíferos bentônicos presentes no trabalho corroboram interpretações relacionadas à reconstrução paleoambiental e de evolução da linha de costa (Horton et al., 2005; Wilson et al., 2008; Callard et al., 2011).
No testemunho T1 (Fig. 4 e 5, tab. 1), da base até $120 \mathrm{~cm}$ de profundidade foi registrada a ocorrência em abundância das espécies calcárias, tais como $\mathrm{Am}$ monia parkinsoniana (Fig. 5.10), A. tepida (Fig. 5.11), incluindo outras calcárias e aglutinantes em menores proporções, como Elphidium excavatum (Fig. 5.12), E. galvestonensis (Fig. 5.13), Cibicides io, Tretomphalus bulloides e Trochammina laevigata. No intervalo entre $110 \mathrm{~cm}$ e o topo do testemunho, observou-se uma diminuição da quantidade das espécies calcárias e aumento das aglutinantes, embora estas últimas estejam em menores proporções. Dentre os aglutinantes, as espécies mais abundantes foram: Ammotium cassis (Fig. 5.6), A. salsum (Fig. 5.7), Trochammina inflata (Fig. 5.8), além de outras, como Ammobaculites exiguus (Fig. 5.4), $\mathrm{Ha}$ plophragmoides wilberti, Ammobaculites spp. (Fig. 5.5), Arenoparrella mexicana (Fig. 5.9), H. manilaensis, Haplophragmoides spp. e Ammobaculites dilatatus (Fig. 5.3).
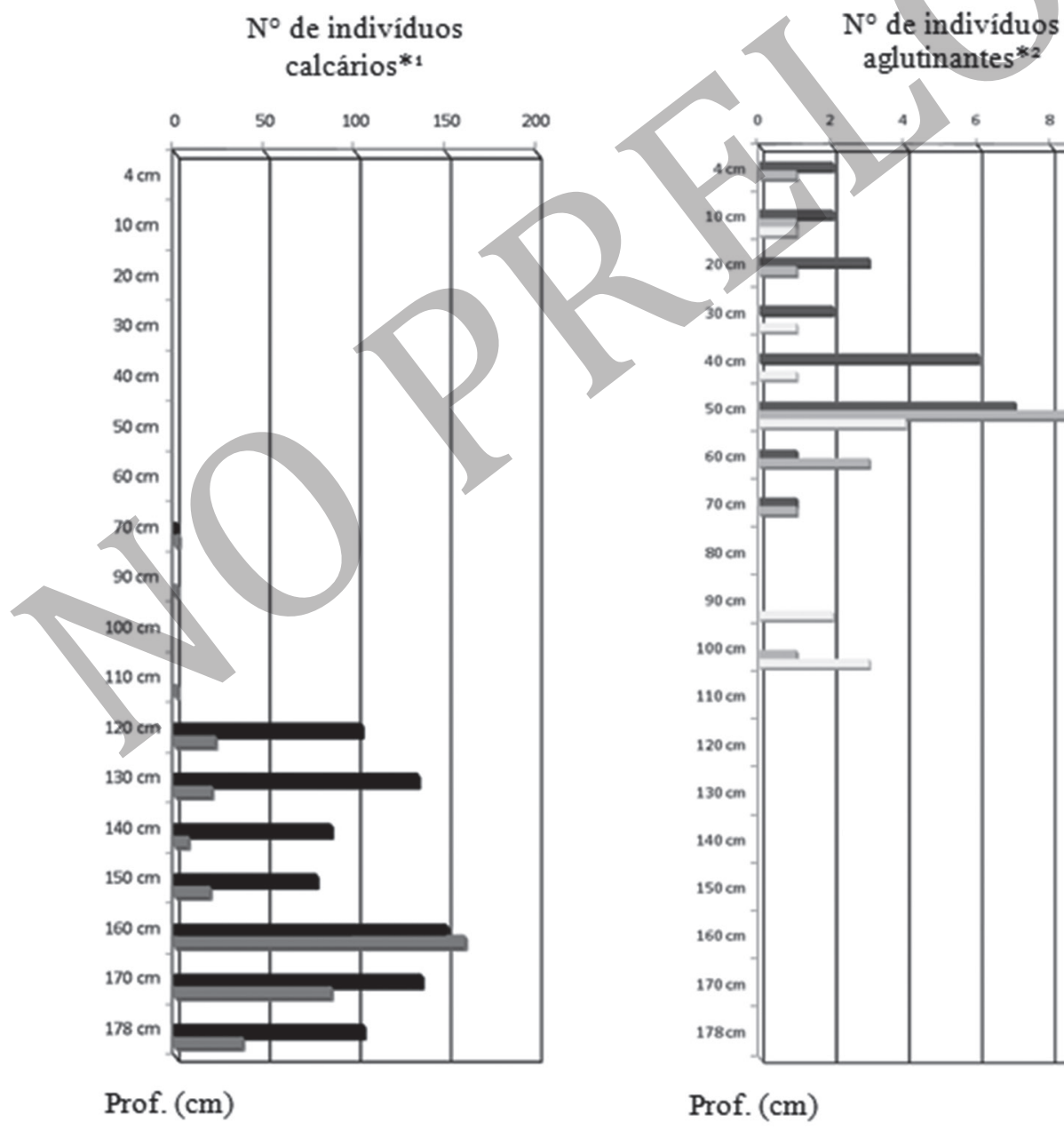

Prof. (cm)

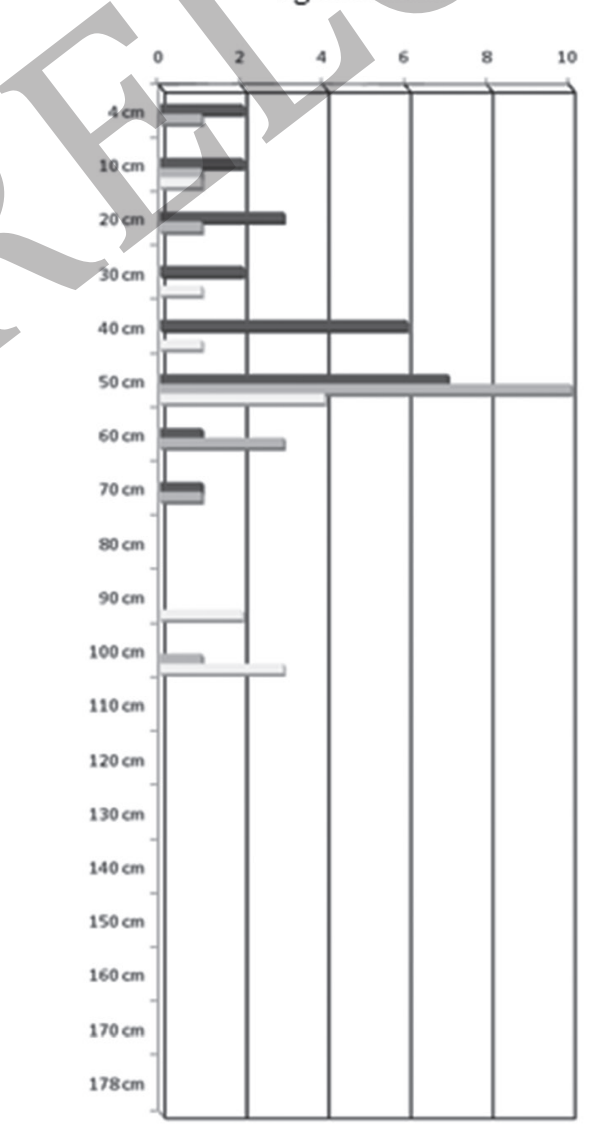

Prof. (cm)

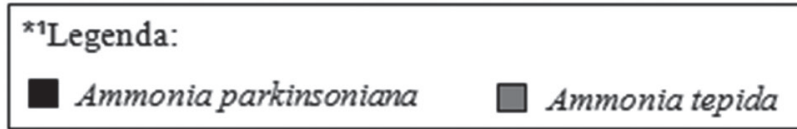

${ }^{* 2}$ Legenda:

Ammotium cassis

Ammotium salsum

Trochammina inflata

Figura 4. Espécies calcárias e aglutinantes do testemunho T1 Maricá. 


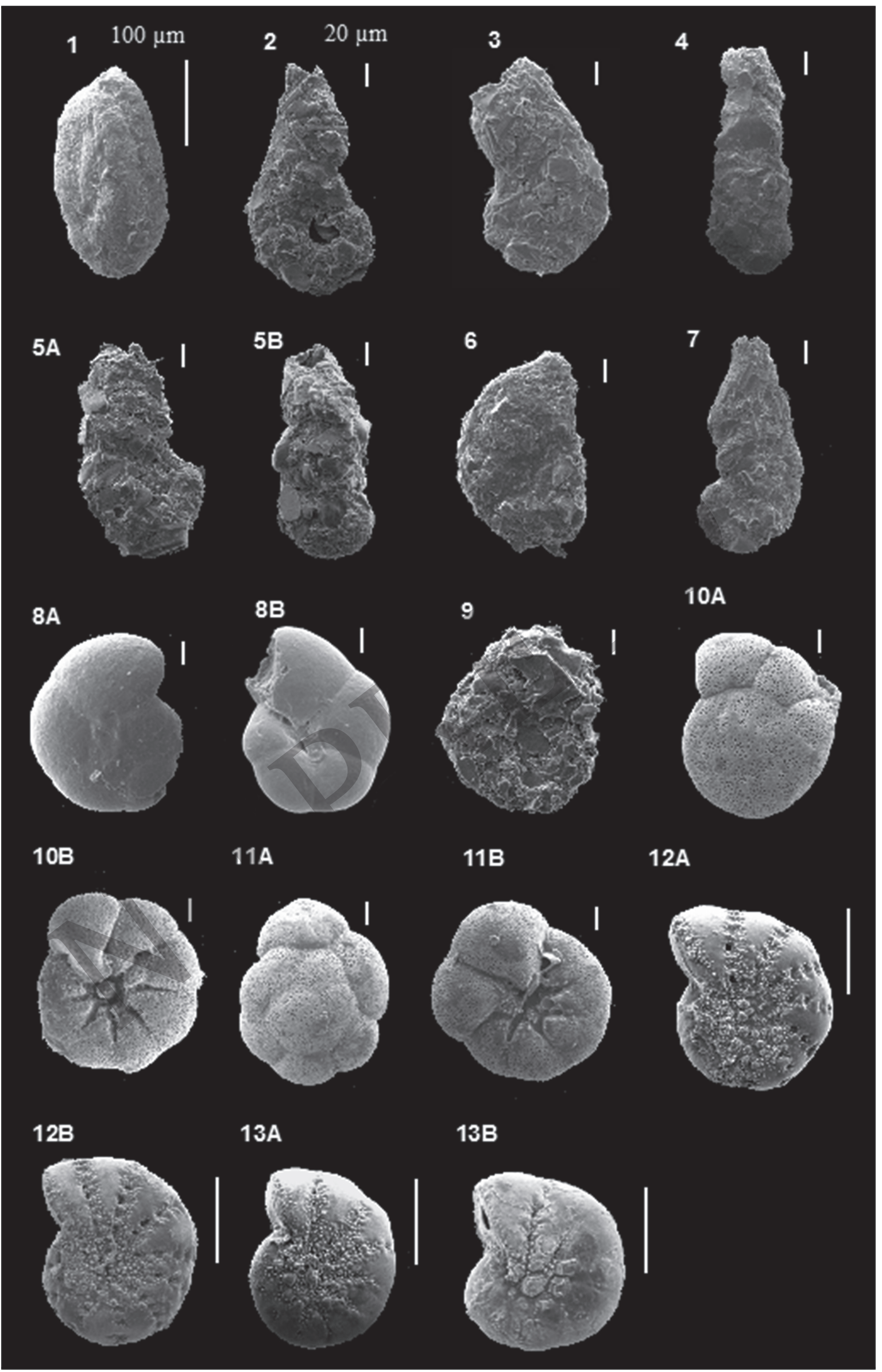

Figura 5. Foraminíferos bentônicos da Laguna de Maricá: 1. Miliammina fusca (Brady), MAR/ T2-10 cm; 2. Ammobaculites agglutinans (d' Orbigny), MAR/ T2-40 cm; 3. Ammobaculites dilatatus (Cushman \& Brönnimann), MAR/ T2-40 cm; 4. Ammobaculites exiguus (Cushman \& Brönnimann), MAR/ T1-40 cm; 5. Ammobaculites SPP., MAR/ T2-40 cm; 6. Ammotium cassis (Parker), MAR/ T2-50 cm; 7. Ammotium salsum (Cushman \& Brönnimann), MAR/ T2-10 cm; 8. Trochammina inflata (Montagu), MAR/ T1-50 cm; 9. Arenoparrella mexicana (Kornfeld), MAR/ T1-40 cm; 10. Ammonia parkinsoniana (d'Orbigny), MAR/ T1-170 cm; 11. Ammonia tepida (Cushman), MAR/ T1-170 cm; 12. Elphidium excavatum (Terquem), MAR/ T1-178 cm; 13. Elphidium galvestonensis (Kornfeld), MAR/ T1-140 cm. Escala = $20 \mu \mathrm{m}$ e $100 \mu \mathrm{m}$. 


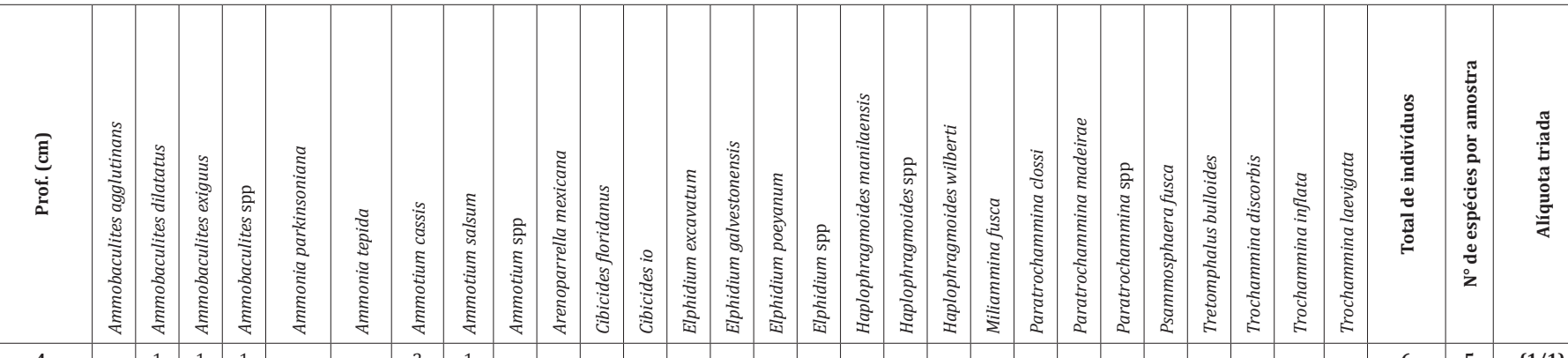

\begin{tabular}{|c|c|c|c|c|c|c|c|c|c|c|c|c|c|c|c|c|c|c|c|c|c|c|c|c|c|c|c|c|c|}
\hline 4 & & 1 & 1 & 1 & & & 2 & 1 & & & & & & & & & & & & & & & & & & & 6 & 5 & $(1 / 1)$ \\
\hline 10 & & 1 & & & & & 2 & 1 & & & & & & & & & & 2 & & & & & & & 1 & & 7 & 5 & $(1 / 1)$ \\
\hline 20 & & & 2 & & & & 3 & 1 & & & & & 1 & & & & 1 & 3 & & & & & & & & & 12 & 7 & $(1 / 1)$ \\
\hline 30 & & & 1 & 3 & & & 2 & & & 2 & & & & & & & 1 & 1 & & & & & & & 1 & & 12 & 8 & $(1 / 1)$ \\
\hline 40 & & & 3 & & & & 6 & & 1 & 3 & & & & & & 1 & 2 & 2 & & & & & & & 1 & & 19 & 8 & $(1 / 1)$ \\
\hline 50 & 1 & 1 & 2 & 2 & & & 7 & 10 & 1 & 2 & & & & & & & 3 & 1 & & & 2 & & & & 4 & & 36 & 12 & $(1 / 1)$ \\
\hline 60 & & & & & & & 1 & 3 & & & & & & & & & & & & & & 1 & & & & & 5 & 3 & $(1 / 1)$ \\
\hline 70 & & & & & 1 & 2 & 1 & 1 & & & & & & & & & & & & & & & & & & & 5 & 4 & $(1 / 1)$ \\
\hline 80 & & & & & & & & & & & & & & & & & & & 1 & & & & & & & & 1 & 1 & $(1 / 1)$ \\
\hline 90 & & & & & & 1 & & & & & & & & & & & & & & 1 & & & & & 2 & & 4 & 3 & $(1 / 1)$ \\
\hline 100 & & & & & & & & 1 & & & & & & & & & & & & & & E & 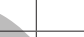 & & 3 & & 4 & 2 & $(1 / 1)$ \\
\hline 110 & & & & 1 & & 1 & & & & & & & & & 4 & & & & & & 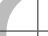 & & 1 & & & & 7 & 4 & $(1 / 1)$ \\
\hline 120 & & & & & 103 & 22 & & & & & & & & & & & & & 1 & & & & 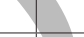 & 1 & & & 127 & 4 & $(1 / 1)$ \\
\hline 130 & & & & & 134 & 20 & & & & & & & & & & & & & & & & & 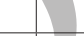 & & & & 154 & 2 & $(1 / 1)$ \\
\hline 140 & & & & & 86 & 7 & & & & & 1 & & & 2 & & & & 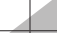 & & & 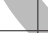 & 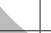 & 1 & & & & 96 & 4 & $(1 / 1)$ \\
\hline 150 & & & & & 78 & 19 & & & & & & 2 & 1 & & & & & & & & & 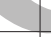 & 1 & & & & 101 & 5 & $(1 / 8)$ \\
\hline 160 & & & & & 150 & 60 & & & & & & 1 & & & & & 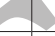 & & & & 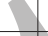 & & & & & 1 & 212 & 4 & $(1 / 8)$ \\
\hline 170 & & & & & 136 & 86 & & & & & & & & 1 & & $<$ & & & & & & 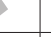 & 1 & & & 1 & 225 & 5 & $(1 / 16)$ \\
\hline 178 & & & & & 104 & 37 & & & & & & & 5 & & & & & & & & 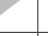 & & & & & & 146 & 3 & $(1 / 16)$ \\
\hline $\begin{array}{l}\text { por } \\
\text { pécie }\end{array}$ & 1 & 3 & 9 & 7 & 792 & 255 & 24 & 18 & 2 & 7 & 1 & 3 & 7 & 3 & & 1 & 5 & 4 & 2 & 1 & 2 & 1 & 2 & 1 & 12 & 2 & 1179 & & \\
\hline
\end{tabular}

O testemunho T2 (Figs. 5 e 6, tab. 2) apresentou A. tepida, entre outras, como Elphidium galvestonensis e distribuição de espécies semelhante ao T1. Da base até E. excavatum. Entre $80 \mathrm{~cm}$ e o topo, observou-se a dimi$90 \mathrm{~cm}$ de profundidade, verificou-se a predominância nuição da quantidade das espécies calcárias e o aumende espécies calcárias como Ammonia parkinsoniana e to das aglutinantes, embora ocorram em menores pro-

Tabela 2. Espécies de foraminíferos no testemunho T2 Maricá.

\begin{tabular}{|c|c|c|c|c|c|c|c|c|c|c|c|c|c|c|c|c|c|c|c|c|c|c|c|c|c|c|c|}
\hline 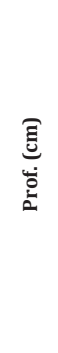 & 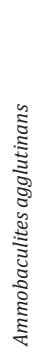 & 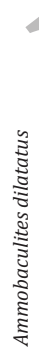 & 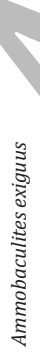 & 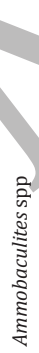 & 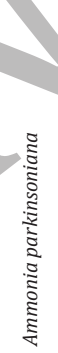 & 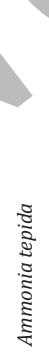 & 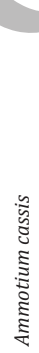 & 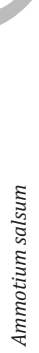 & 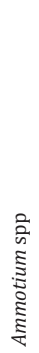 & 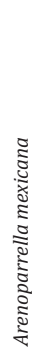 & 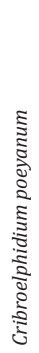 & 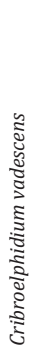 & 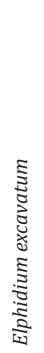 & 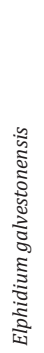 & 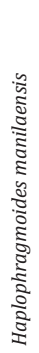 & 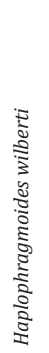 & 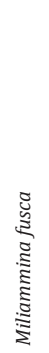 & 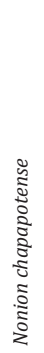 & 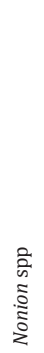 & 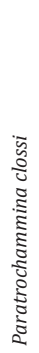 & 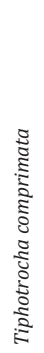 & 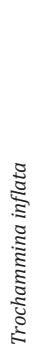 & 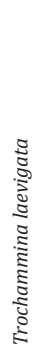 & 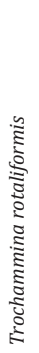 & 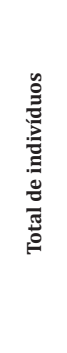 & 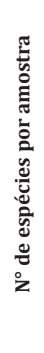 & $\begin{array}{l}\frac{\pi}{0} \\
\frac{\pi}{E} \\
\frac{\pi}{0} \\
\frac{E}{2} \\
\end{array}$ \\
\hline 4 & & & & & & & & 1 & & & & & & & & 1 & 17 & & & & & & & & 19 & 3 & $(1 / 1)$ \\
\hline 10 & & 5 & 1 & 7 & & & 2 & 14 & 1 & 2 & & & & & & 2 & 21 & & & & & 2 & & & 57 & 10 & $(1 / 1)$ \\
\hline 20 & & & & & 1 & & 1 & & & & & & & & 1 & & 1 & & & & & & & & 4 & 4 & $(1 / 1)$ \\
\hline 30 & 2 & 2 & 2 & 6 & & & 10 & 11 & 1 & 1 & & & & & & & & & & 2 & & 3 & & & 40 & 10 & $(1 / 1)$ \\
\hline 40 & 2 & 4 & & 9 & & & 7 & 2 & & & & & & & & & & & & 1 & 2 & 4 & & & 31 & 8 & $(1 / 1)$ \\
\hline 50 & & 2 & & 2 & & & 13 & 4 & & 2 & & & & & & & & & & & & & & & 23 & 5 & $(1 / 1)$ \\
\hline 60 & & & & 4 & & & 3 & & & 1 & & & & & & & & & & & & & & & 8 & 3 & $(1 / 1)$ \\
\hline 70 & & & & & 3 & & & & & & & & & & & & & & & & & & & & 3 & 1 & $(1 / 1)$ \\
\hline 80 & & & & & 20 & 2 & & & & & & & & & & & & & & & & & & & 22 & 2 & $(1 / 1)$ \\
\hline 90 & & & & & 104 & 5 & & & & & & & & & & & 1 & & & & & & & & 110 & 3 & $(1 / 1)$ \\
\hline 100 & & & & & 166 & 41 & & & & & & & 2 & & & & & & 2 & & & & 1 & 1 & 213 & 6 & $(1 / 16)$ \\
\hline 110 & & & & & 133 & 105 & & & & & & 1 & & & & & & & & & & & & & 239 & 3 & $(1 / 2)$ \\
\hline 120 & & & & & 148 & 90 & & & & & & & 1 & & & & & & & & & & 2 & & 241 & 4 & $(1 / 1)$ \\
\hline 130 & & & & & 314 & 108 & & & & & 1 & & 1 & 5 & & & & & & & & & 4 & & 433 & 6 & $(1 / 1)$ \\
\hline 140 & & & & & 121 & 23 & & & & & & & 1 & & & & & 1 & & & & & & & 146 & 4 & $(1 / 2)$ \\
\hline 150 & & & & & 105 & 40 & & & & & & & & 3 & & & & 1 & & & & & & & 149 & 4 & $(1 / 1)$ \\
\hline 160 & & & & & 125 & 23 & & & & & & & 2 & & & & & & & & & & & 1 & 151 & 4 & $(1 / 1)$ \\
\hline 168 & & & & & 74 & 47 & & & & & & & & 1 & & & & 1 & & & & & & & 123 & 4 & $(1 / 1)$ \\
\hline $\begin{array}{l}\text { por } \\
\text { écie }\end{array}$ & 4 & 13 & 3 & 28 & 1314 & 484 & 36 & 32 & 2 & 6 & 1 & 1 & 7 & 9 & 1 & 3 & 40 & 3 & 2 & 3 & 2 & 9 & 7 & 2 & 2012 & & \\
\hline
\end{tabular}


porções, entre as quais se destacam: Miliammina fusca (Fig. 5.1), Ammotium cassis, A. salsum, Ammobaculites spp., além de Ammobaculites dilatatus, Trochammina inflata, T. laevigata, Arenoparrella mexicana, Ammoba- culites agglutinans (Fig. 5.2), A. exiguus, Haplophragmoides wilberti, Nonion chapapotense e Paratrochammina clossi.

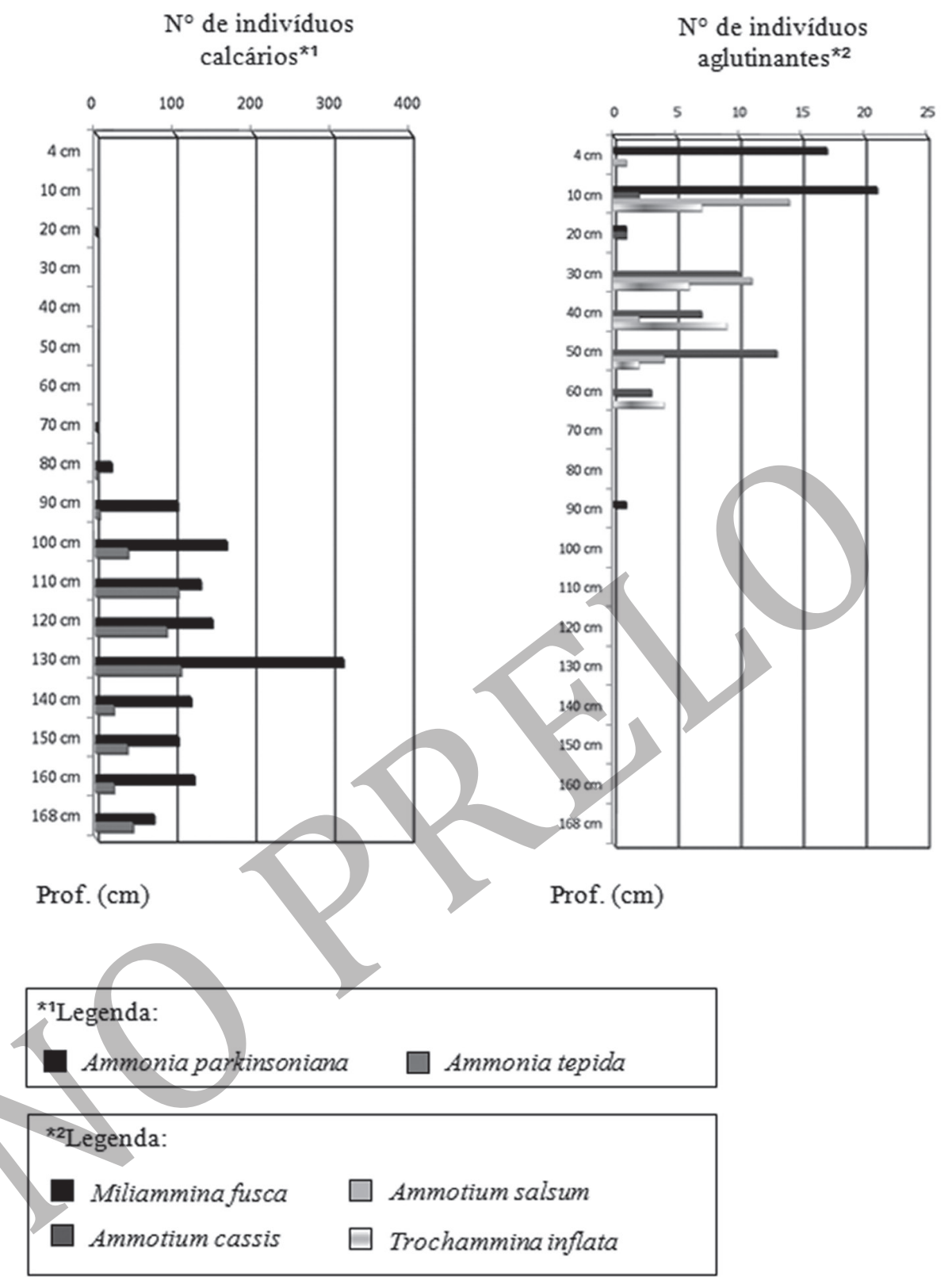

Figura 6. Espécies calcárias e aglutinantes do testemunho T2 Maricá.

Em ambos os testemunhos, na metade inferior foram registradas abundantes espécies calcárias associadas à alternância de lama siltosa e lama arenosa com fragmentos de conchas, sugerindo influência marinha de média a alta energia hidrodinâmica, ocasionada por ondas de tempestades e variação do nível do mar. $\mathrm{Na}$ metade superior de ambos os testemunhos foi verificada a predominância de espécies aglutinantes associadas à lama siltosa com a presença de alguns micromoluscos, sugerindo baixa energia hidrodinâmica.

\subsection{Reconstrução paleoambiental da Laguna de Maricá}

Em ambos os testemunhos a biofácies Ap-At (Am- monia parkinsoniana-A. tepida) (Figs. 7 e 8) é caracterizada pela abundância da microfauna de foraminíferos calcário-hialinos, como A. parkinsoniana e A. tepida associada à fáceis sedimentar composta pela intercalação de lama siltosa e lama arenosa, com fragmentos de conchas. Esta biofácies caracterizou-se por representar um ambiente restrito, com influência de águas marinhas, possuindo assim, características de circulação hidrodinâmica de estuário e/ou baía.

$\mathrm{Na}$ biofácies Ac-As (Ammotium cassis-A. salsum) (Fig. 7 e 8), em ambos os testemunhos, verificou-se diminuição na quantidade de foraminíferos calcário-hialinos e aumento das espécies aglutinantes associadas à fáceis sedimentar de lama siltosa. Esta biofácies 
corresponde provavelmente à fase de pós-fechamento (aproximadamente 1040-970 cal anos AP) da barreira arenosa interna da Laguna de Maricá, caracterizando ambiente de baixa energia hidrodinâmica e de diminuição nas concentrações de salinidade.

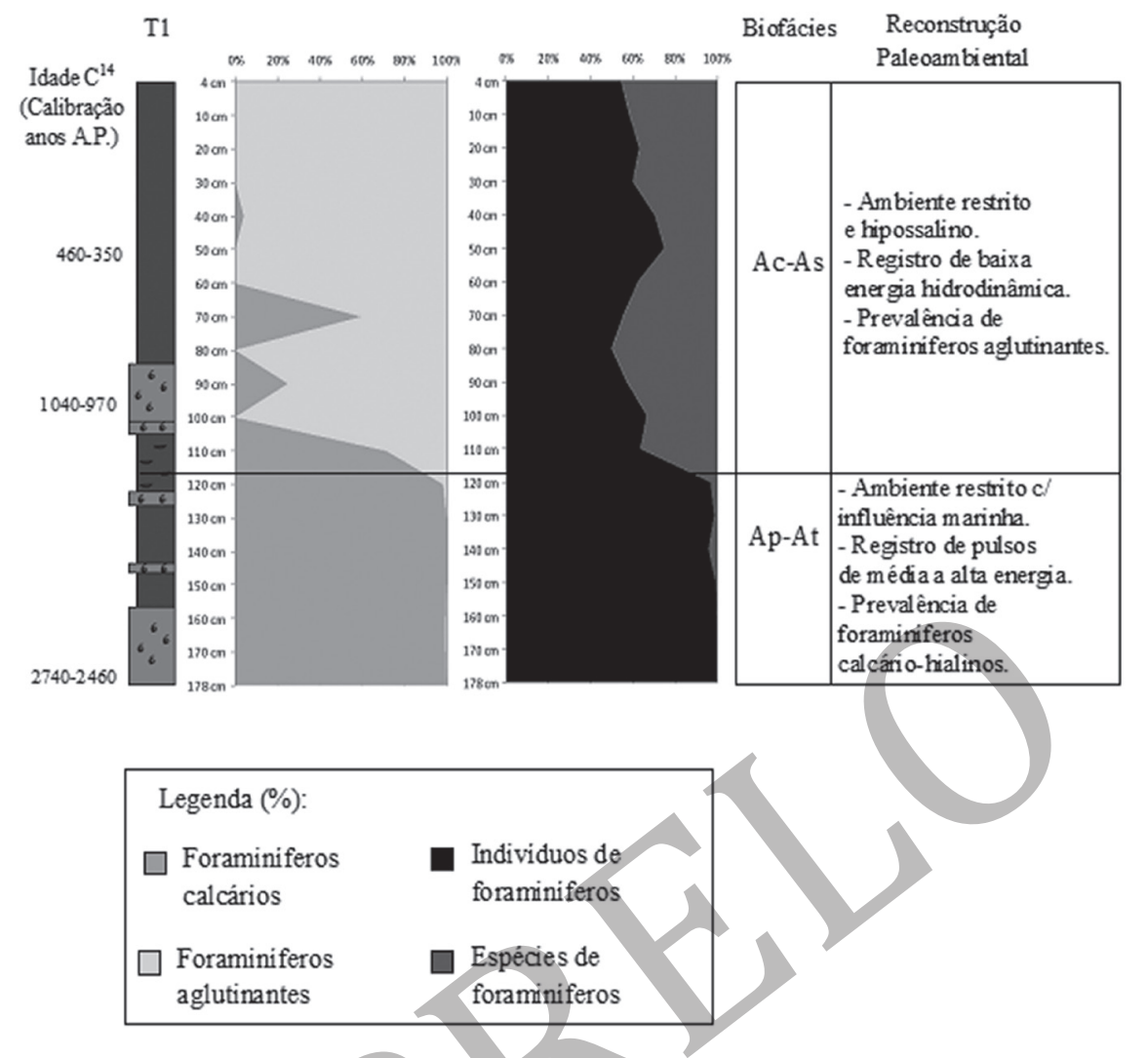

Figura 7. Reconstrução paleoambiental do T1 Maricá.

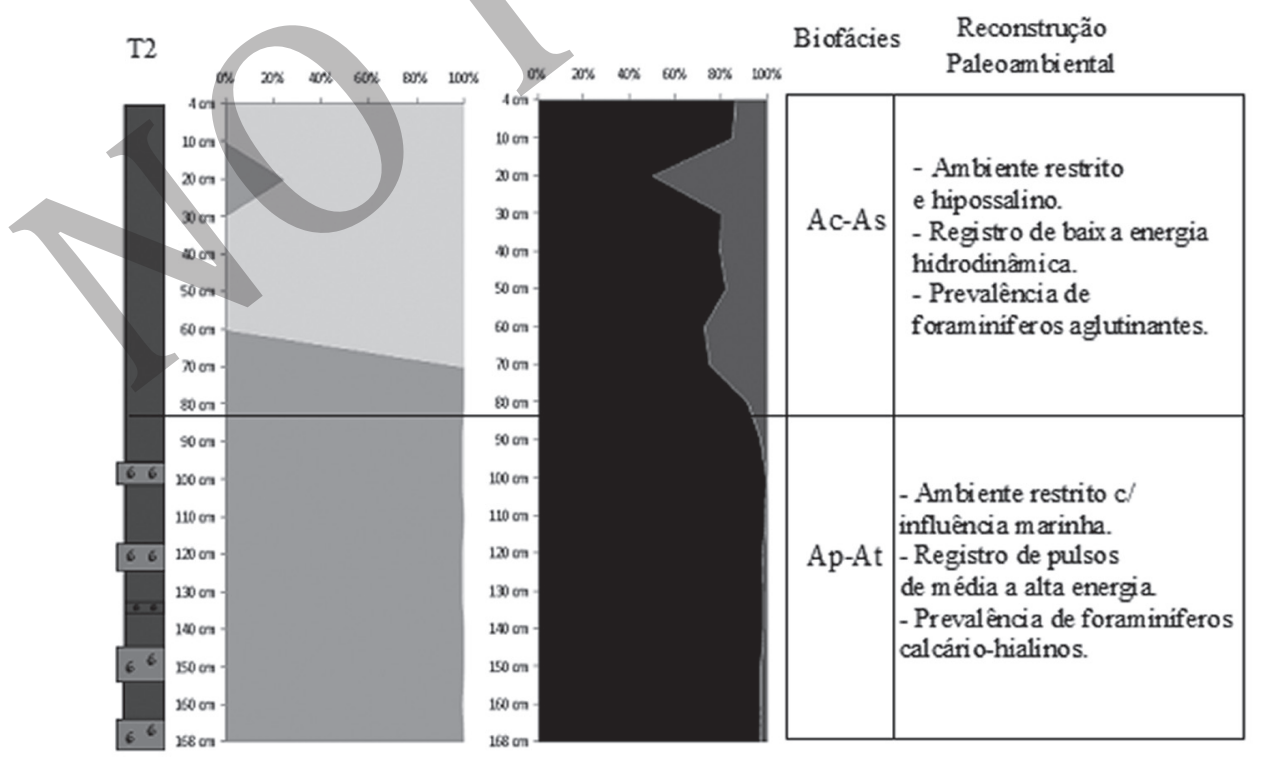

\begin{tabular}{|lc|}
\hline Legenda (\%): & \\
$\begin{array}{l}\text { Foraminiferos } \\
\text { calcários }\end{array}$ & $\begin{array}{l}\text { Individuos de } \\
\text { foraminiferos }\end{array}$ \\
$\begin{array}{l}\text { Foraminiferos } \\
\text { aglutinantes }\end{array}$ & $\square \begin{array}{l}\text { Espécies de } \\
\text { foraminiferos }\end{array}$ \\
\hline
\end{tabular}

Figura 8. Reconstrução paleoambiental do T2 Maricá. 
A partir dos dados da assembleia de foraminíferos, da composição sedimentológica e das datações tornou-se possível estabelecer estágios referentes à evolução final da Laguna de Maricá. Para este trabalho, o registro nos testemunhos possibilitou a divisão de dois estágios e uma fase de transição:

- Estágio I: Nesta fase, datada há aproximadamente 2740-2460 cal anos AP, ocorreu o registro de média a alta energia hidrodinâmica e com influência marinha, representado respectivamente pela alternância de camadas de lama siltosa e lama arenosa, com conchas quebradas e presença em abundância das espécies A. parkinsoniana e A. tepida. Neste estágio, provavelmente a barreira arenosa interna pleistocênica da Laguna de Maricá possuía comunicação com o mar e permitia assim, o intercâmbio de influência marinha (Fig. 9).

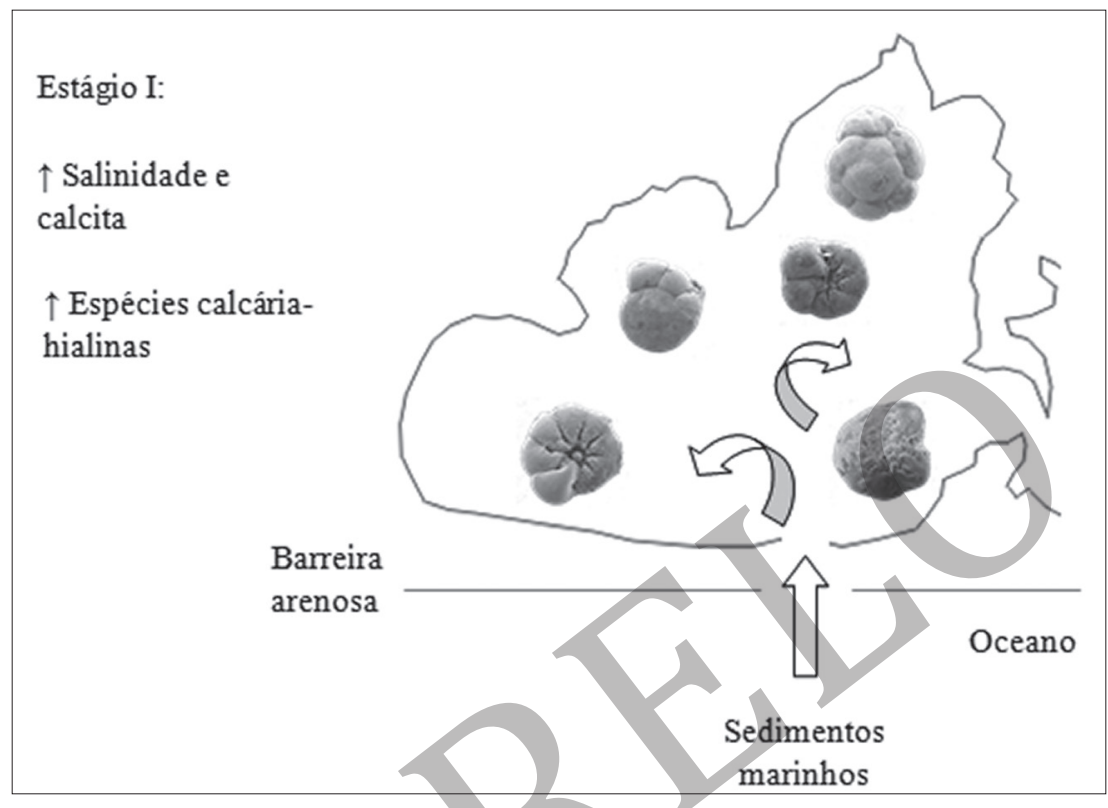

Figura 9. Estágio I da Laguna de Maricá.

- Fase de transição: Há aproximadamente 1040$970 \mathrm{cal}$ anos A.P., em particular no intervalo entre $90-80 \mathrm{~cm}$ registrado no $\mathrm{T} 2$ (testemunho mais próximo do cordão arenoso), ocorreu um provável fechamento da barreira arenosa, sendo observada uma brusca diminuição na quantidade das espécies $A$. parkinsoniana e $A$. tepida, além de outras calcárias acompanhadas por uma mudança na granulometria dos sedimentos tendendo a uma lama mais siltosa. Nesta fase, possivelmente começou a haver uma diminuição nas concentrações de salinidade e calcita. (Fig. 10).

Fase de transição:

$\downarrow$ Salinidade e calcita

$\downarrow$ Espécies calcáriahialinas

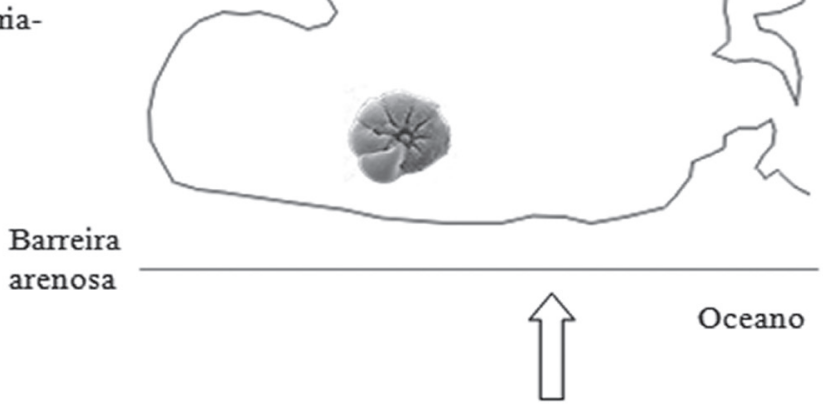

Fechamento da barreira arenosa 
- Estágio II: O possível fechamento total da barreira arenosa interna, incluindo condição de baixa energia hidrodinâmica da laguna, diminuição de calcita e aumento de uma condição mais hipossalina (proporcionado por um balanço hidrológico de aporte fluvial e clima), favoreu a ocorrência de espécies aglutinantes, como Ammotium cassis, A. salsum, Trochammi- na inflata, Miliammina fusca, Ammobaculites spp., entre outras. No intervalo de aproximadamente $50 \mathrm{~cm}$, a datação entre $460-350 \mathrm{cal}$ anos AP corroborou a interpretação de que a mudança brusca registrada anteriormente de foraminíferos calcários para aglutinantes sugere uma sequência cronológica deposicional gradativa (Fig. 11).

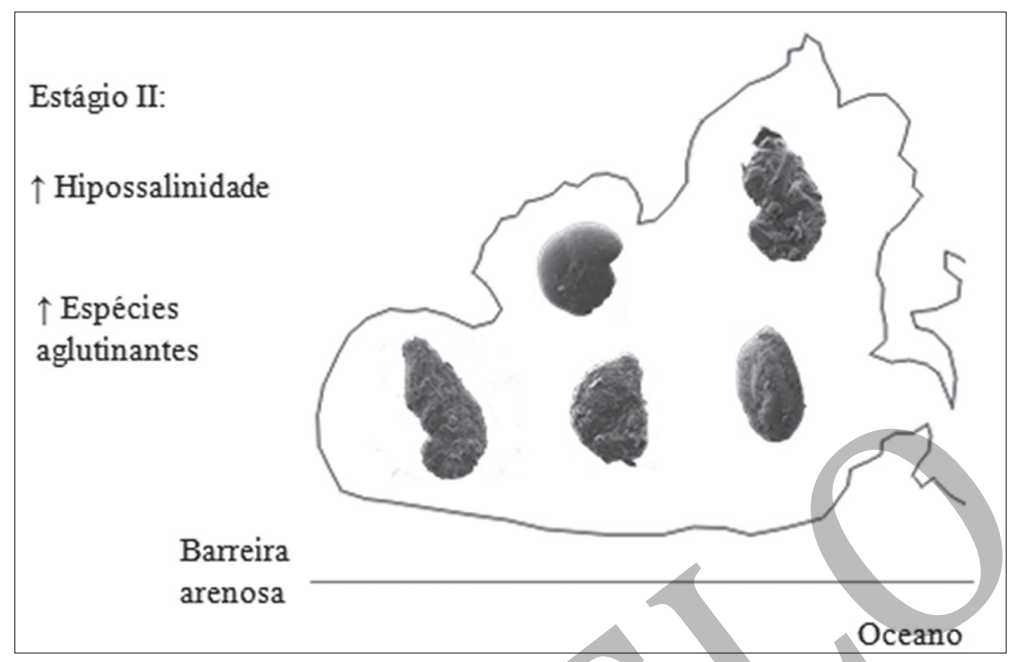

Figura 11. Estágio II da Laguna de Maricá.

Analisando todos os processos envolvidos na La- (estágio I) e (ii) tendência salobra (estágio II), baseadoguna de Maricá foi possível elaborar um diagrama mos- -se em um dos elementos mais importantes, a barreira trando as duas situações: (i) preenchimento marinho arenosa que influenciou em tais condições (Fig. 12).

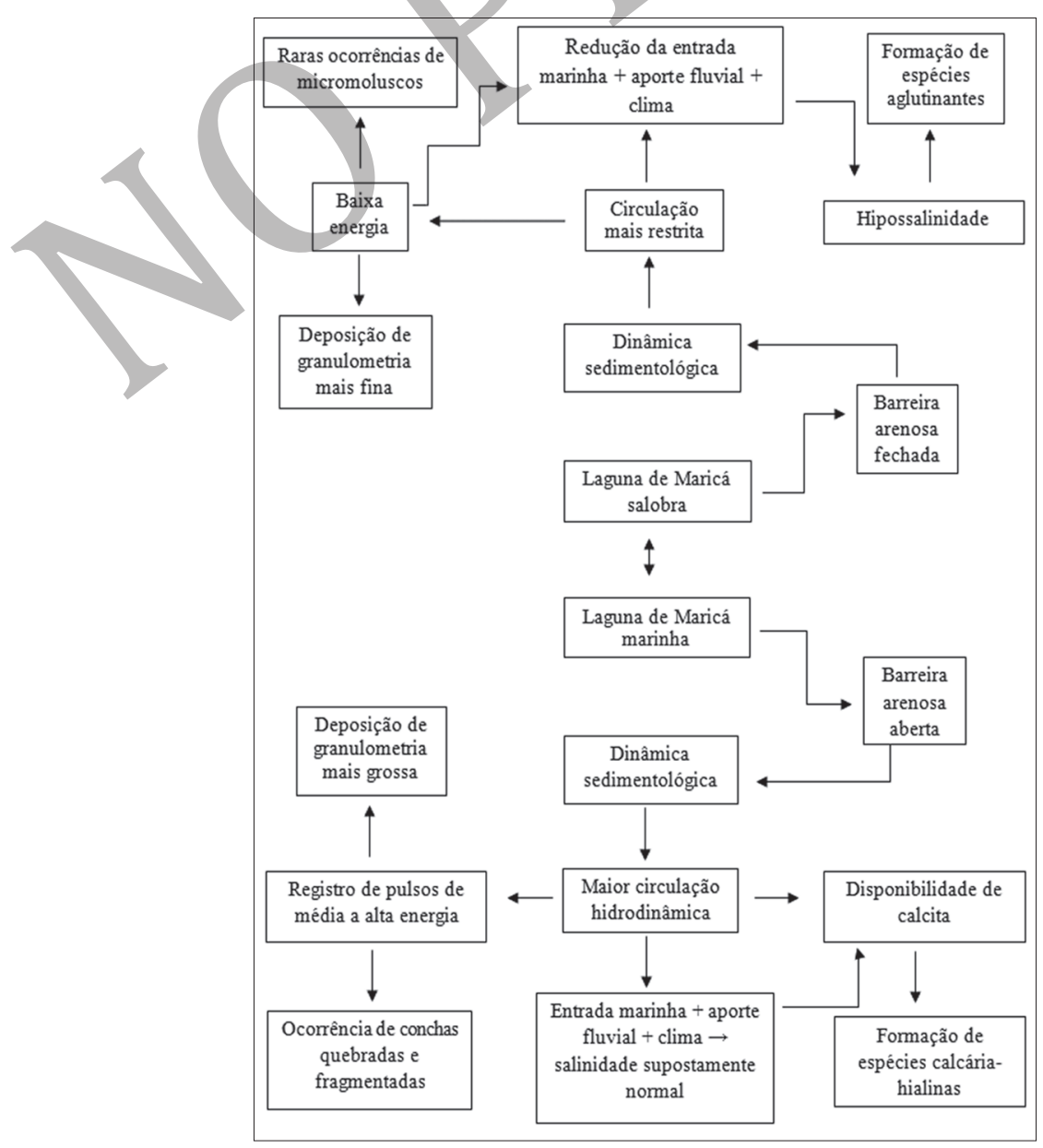

Figura 12. Modelo simplificado dos processos da Laguna de Maricá. 


\subsection{Carbono orgânico total (COT)}

Em regiões de ambiente restrito, como baías, lagunas e estuários, a mensuração do COT é de suma importância, pois estes ambientes são propícios ao aumento da acidez decorrente de processos fermentativos ocasionados por efluentes domésticos e industriais, servindo assim, como ferramenta indireta para avaliar o impacto do grau de acidez na dissolução das tecas de foraminíferos calcários (Le Cadre et al., 2003; Hayward et al., 2004; Buzas-Stephens \& Buzas, 2005).

Em geral, os valores do carbono orgânico total
(COT) registrados ao longo dos testemunhos foram baixos, possuindo um aumento no em torno de $50 \mathrm{~cm}$ ao topo (Fig. 13), visto que os valores de COT variaram respectivamente entre $0,07-3,60 \%$ no $\mathrm{T} 1$ e entre 0,03 $1,90 \%$ no T2.

As concentrações de COT quando comparadas a assembleia de foraminíferos (Tabelas 1 e 2), não demonstraram correspondência, pois em $50 \mathrm{~cm}$ aproximadamente em que foi registrado o aumento do COT, se distanciou da mudança no tipo de microfauna calcária e aglutinante ocorrido entre $120-110 \mathrm{~cm}$ no T1 e $90-80 \mathrm{~cm}$ no $\mathrm{T} 2$.

\section{Legenda: $\leadsto$-COT (\%)}

T1

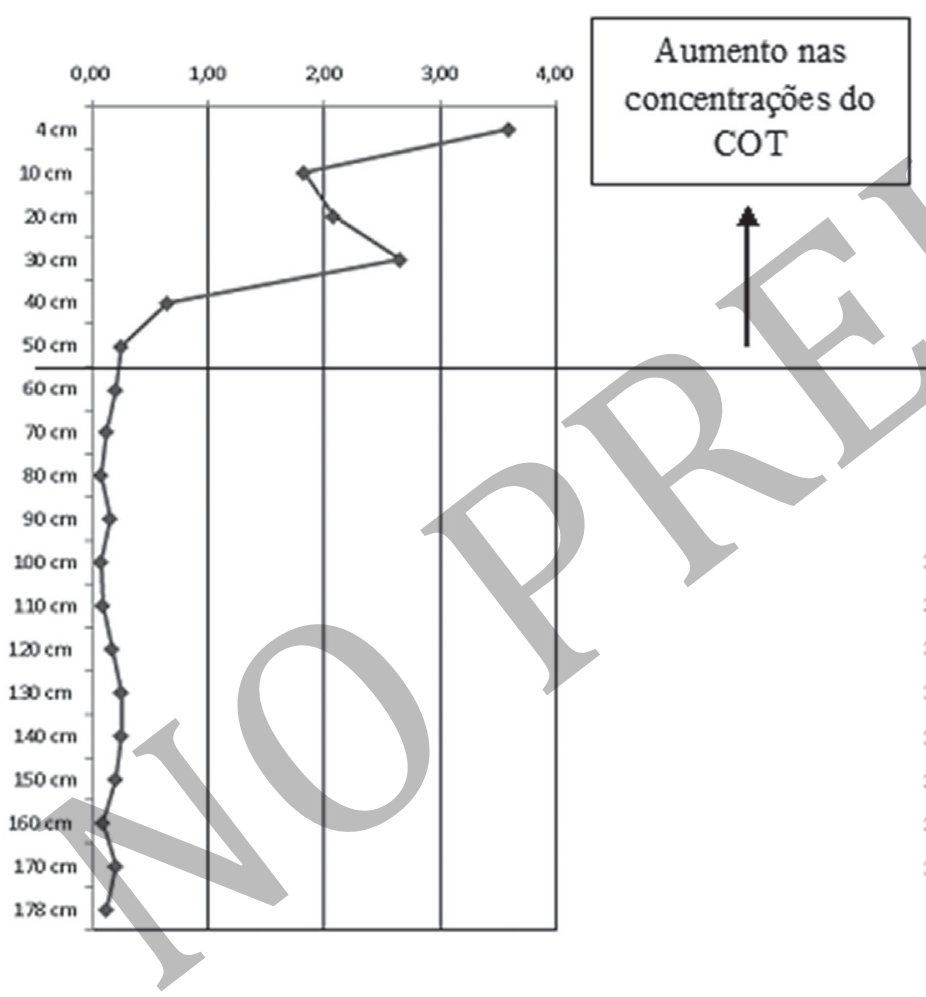

T2

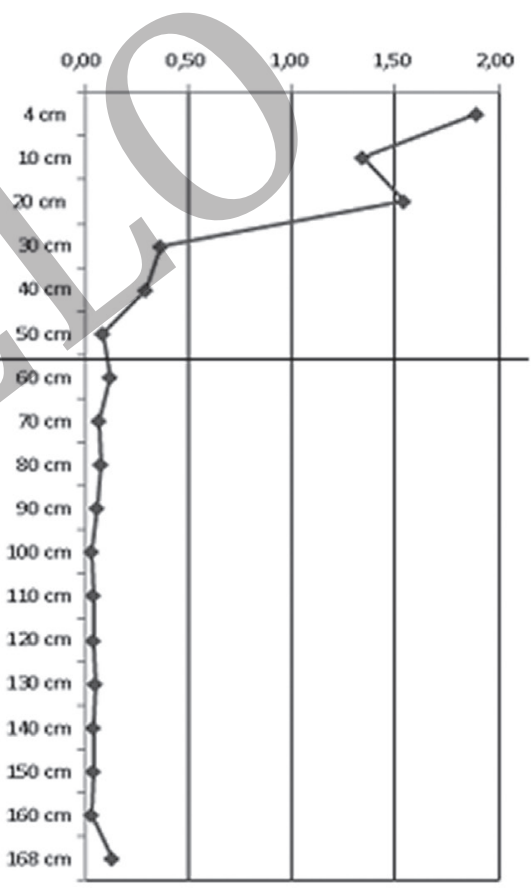

Figura 13. Carbono Orgânico Total (\%) nos testemunhos da Laguna de Maricá.

\section{Discussão}

$\mathrm{Na}$ metade inferior dos testemunhos, ocorrem principalmente foraminíferos calcário-hialinos como A. parkinsoniana e $A$. tepida associadas à alternância de lama siltosa e lama arenosa, com fragmentos de conchas, sugerindo registro ocasionado por ondas de tempestade. Segundo Walton \& Sloan (1990) o gênero Ammonia, incluindo as formas A. parkinsoniana e $A$. tepida, é capaz de sobreviver a condições extremas de baixa $\left(0-5^{\circ} \mathrm{C}\right)$ e alta $\left(35^{\circ} \mathrm{C}\right)$ temperatura e salinidade variável $(<1 \%$ e $>90 \%$ ), possui ampla distribuição geográfica, preferencialmente em baías, golfos, enseadas, lagunas e estuários. Frontalini \& Coccioni (2008) documentaram na Laguna Santa Gilla (Cagliari, Itália) que $A$. parkinsoniana e A. tepida embora apresentem preferência por ambientes limpos e de baixas concentrações de poluentes, são capazes de tolerar aumento nas concentrações de metais pesados e matéria orgânica. Hart \& Kaesler (1986) descreveram a ocorrência dos gêneros Ammonia e Elphidium no canal de maré e na laguna da península de Yucatan, México, visto que a distribuição desta associação indica uma gradual transição a partir das condições marinhas costeiras para condições restritas lagunares. No presente trabalho, a abundância de $A$. parkinsoniana e $A$. tepida, incluindo a ocorrência do gênero Elphidium registrada nos testemunhos da Laguna de Maricá, relaciona-se ao possível período da laguna em comunicação com o mar representada pela biofácies Ap-At.

0 estado de preservação das conchas em quebradas e fragmentadas na biofácies Ap-At, corrobora a in- 
terpretação paleoambiental, indicando registro de alta a média energia hidrodinâmica ocasionada por ondas de tempestade e variação do nível do mar. Segundo Fürsich \& Kirkland (1986) e Simões \& Torello (2003), a disposição das conchas desarticuladas, quebradas e fragmentadas está em função dentre vários fatores da alta energia do ambiente e transporte.

$\mathrm{Na}$ porção mediana dos testemunhos (aproximadamente 1040-970 cal anos AP), o paleoambiente inferido constituiu-se em um ambiente restrito, com possível fechamento total da barreira arenosa interna, denominado de fase de transição. Nesta fase, infere-se que houve uma diminuição nas concentrações de salinidade e calcita, devido à diminuição na quantidade de foraminíferos calcários. Segundo Boltovskoy (1965) e Boltovskoy et al. (1991) cada espécie de foraminífero apresenta um limite mínimo ou específico de tolerância de salinidade para a sua distribuição e sobrevivência, sendo a concentração de $7 \%$, um valor considerado mínimo para o desenvolvimento do gênero Ammonia. Desta forma, nesta etapa de transição da Laguna de Maricá, a salinidade tendeu a ser igual a inferior a 7\%o.

A metade superior dos testemunhos composta por lama siltosa apresenta raros exemplares de micromoluscos e ocorrência predominante de foraminíferos aglutinantes, como Ammotium cassis, A. salsum, Trochammina inflata, Miliammina fusca, Ammobaculites spp., seguida de outras em menores proporções, como Ammobaculites exiguus, Haplophragmoides wilberti, Arenoparrella mexicana, H. manilaensis, Haplophragmoides spp., A. dilatatus, entre outros, indicando assim, registro de baixa energia hidrodinâmica e tendência à hipossalinidade. Segundo um estudo realizado por Bomfim et al. (2010) a associação de foraminíferos bentônicos registrados no fundo da Laguna de Maricá, a exemplo das espécies dominantes, como Miliammina fusca, Miliammina spp., Haplophragmoides spp., Ammobaculites dilatatus, Ammobaculites spp., entre outras, caracterizam um ambiente parálico, de baixa energia hidrodinâmica e de salinidade, sendo que neste não foi observado impacto antrópico acentuado. De acordo com Ellison \& Murray (1987) as espécies do gênero Ammobaculites e Ammotium, como A. cassis e A. salsum são toleráveis às mudanças na temperatura e salinidade a cada estação do ano, distribuindo-se preferencialmente em substratos lamosos ricos em matéria orgânica, como baías, lagunas e estuários. Segundo Scott et al. (2001) na zona de transição compreendida entre a Baía de Miramichi (Canadá) e o estuário, ocorrem as espécies $A$. cassis e A. salsum como dominantes, sendo que a $A$. cassis relaciona-se à altas concentrações de material particulado em suspensão. Cearreta \& Murray (1996) documentaram dentre várias espécies, a ocorrência de $M$. fusca e T. inflata como indicadoras de água salobra no estuário de Santoña (Espanha).

Quantidades significativas de carbono orgânico total (COT) podem ser encontradas em ambientes lamosos como em determinadas áreas de lagunas, baías e estuários, onde ocorre o aporte de grandes quantidades de efluentes industriais, domésticos ou da própria ação natural de decomposição de vegetais, favorecendo a redução do pH, em razão dos processos fermentativos e assim dissolvendo as tecas calcárias (Alve, 1995, Murray \& Alve, 1999; Buzas-Stephens et al., 2011).

No presente trabalho, os valores de COT em geral apresentaram-se baixos, mas com aumento na profundidade de $50 \mathrm{~cm}$ em ambos os testemunhos ao topo. A mudança na microfauna calcária para aglutinante no meio dos testemunhos aproximadamente $(96-94 \mathrm{~cm}$, 1040-970 cal anos AP) não demonstrou relação com o aumento do COT, mas referiu-se ao fechamento da barreira arenosa interna da Laguna de Maricá, e por esta razão, favoreceu um ambiente de baixa energia hidrodinâmica e de salinidade para a colonização das espécies aglutinantes.

\section{Conclusões}

A análise da microfauna de foraminíferos bentônicos em associação aos dados sedimentológicos registrados nos testemunhos da Laguna de Maricá, RJ, permitiu realizar uma reconstrução paleoambiental e de evolução da linha de costa, sendo apresentados os seguintes aspectos.

A mudança na composição da associação de foraminíferos calcário-hialinos para aglutinantes em direção ao topo dos testemunhos ocorreu em razão do completo fechamento (1040-970 cal anos AP) das áreas descontínuas da barreira arenosa interna da Laguna de Maricá.

A ocorrência de foraminíferos em sua maioria calcário-hialinos, como Ammonia parkinsoniana e $A$. tepida, associada à intercalação de lama siltosa e lama arenosa, na metade inferior dos testemunhos, indica ambiente restrito, com influência marinha registrada em níveis de conchas quebradas e fragmentadas representativos de pulsos de média a alta energia ocasionadas pela ação de ondas de tempestades.

Na metade superior dos testemunhos, foi verificada a presença de espécies aglutinantes, como Ammotium cassis, A. salsum, Trochammina inflata, Miliammina fusca, Ammobaculites spp., associada à ocorrência de lama siltosa, incluindo raros exemplares de micromoluscos, indicando ambiente de baixa energia hidrodinâmica e condição hipossalina.

As concentrações de COT (\%) apresentaram em geral baixos valores, com exceção do intervalo de 50 $\mathrm{cm}$ ao topo dos testemunhos que exibiu certo aumento, e quando comparadas a mudança na assembleia de foraminíferos calcários para aglutinantes não apresentaram correspondência.

Agradecimentos - A Cleverson Guizan Silva, pela colaboração na coleta de campo, João Graciano Mendonça Filho, pelas análises geoquímicas, Laboratório de Geoprocessamento/ Sistema de Análise Geoambiental SAGA/UFRJ, pelo auxílio 
na confecção do mapa e ao apoio da Coordenação de Aperfeiçoamento de Pessoal de Nível Superior (CAPES).

\section{Referências}

Alve, E. 1995. Benthic foraminiferal distribution and recolonization of formerly anoxic environments in Dramrnensfjord, southern Norway. Marine Micropaleontology, 25: 169-186.

Barbiére, E. \& Coe Neto, R. 1999. Spatial and temporal of rainfall of the East Fluminense coast and Atlantic Serra do Mar, State of Rio de Janeiro, Brazil. In: Knoppers, B., Bidone, E. D. \& Abraão, J. J. (Eds.). Environmental Geochemistry of Costal Lagoon Systems, Rio de Janeiro, Brazil. Niterói, Universidade Federal Fluminense - UFF. Série Geoquímica Ambiental, 6, p. 47-56.

Blázquez, A.M. \& Usera, J. 2010. Palaeoenvironments and Quaternary foraminifera in the Elx Coastal Lagoon (Alicante, Spain). Quaternary International, 221: 68-90.

Boltovskoy, E. 1965. Los foraminíferos recientes. $1^{\text {a }}$ ed. Buenos Aires, Editorial Universitaria de Buenos Aires, 510p.

Boltovskoy, E., Scott, D.B. \& Medioli, F.S. 1991. Morphological variations of benthic foraminiferal tests in response to changes in ecological. Journal of Paleontology, 65(2): 175-185.

Bomfim, C.S., Vilela, G.C. \& Guedes, D.C. 2010. Foraminíferos bentônicos em sedimentos de fundo da lagoa de Maricá, Estado do Rio de Janeiro. Anuário do Instituto de Geociências - UFRJ, 33: 9-19.

Bruno, R.L.M. 2012. Reconstrução paleoambiental nas lagunas de Maricá e Saquarema, RJ com base em foraminíferos. Rio de Janeiro, 180p. Tese de Doutorado, Programa de Pós-graduação em Geologia, Instituto de Geociências, Universidade Federal do Rio de Janeiro.

Buzas-Stephens, P. \& Buzas, M.A. 2005. Population dynamics and dissolution of foraminifera in Nueces Bay, Texas. Journal of Foraminiferal Research, 35(3): 248-258.

Buzas-Stephens, P., Buzas, M.A. \& Elliot, B.A. 2011. Foraminiferal population response to fluctuating inflow into Nueces Bay, Texas. Journal of Foraminiferal Research, 4(1): 14-21.

Callard, S.L., Gehrels, W.R., Morrison, B.V. \& Grenfell, H.R. 2011. Suitability of salt-marsh foraminifera as proxy indicators of sea level in Tasmania. Marine Micropaleontology, 79: 121-131.

Carter, R.W.G. 1988. Conceptual model of coarse clastic barrier formation from multiple sediment sources. Geography Review, 78: 219-238.

Cearreta, A. \& Murray, W. 1996. Holocene paleoenvironmental and relative sea-level changes in the Santoña Estuary, Spain. Journal of Foraminiferal Research, 26 (4): 289-299.

Cearreta, A., Alday. M., Freitas, M.C. \& Andrade, C. 2007. Post glacial foraminifera and paleoenvironments of the Melides Lagoon (SW) Portugal: towards a regional model of coastal evolution. Journal of Foraminiferal Research, 37(2): 125-135.

Davis Jr., R.A., \& Kuhn, B.J. 1985. Origin and development of Anclote Key, West-Peninsular Florida. Marine Geology, 63: 153-171.

Dias, F.F., Castro, J.W.A., Seoane, J.C.S. \& Camargo, L.H.R. 2009. Indicadores de mudanças climáticas e de variações do nível do mar na costa do Rio de Janeiro: Aquecimento ou Resfriamento? Revista Eletrônica de Geografia, 1: 21-32.

Ellison, R.L. \& Murray, J.W. 1987. Geographical variation in the distribution of certain agglutinated foraminifera along the North Atlantic margins. Journal of Foraminiferal Research, 17(2): 123-131.

Fatela, F. \& Taborba, R. 2002. Confidence limits of species proportions in microfossil assemblages. Marine Micropaleontology, 45: 169-174.

FEEMA - Fundação Estadual de Engenharia do Meio Ambiente. 1995. Plano Diretor da APA de Maricá. Governo do Estado do Rio de Janeiro.

Flexor, J.M., Martin, L., Suguio, K. \& Dominguez, J.M.L. 1984. Gênese dos cordões litorâneos da parte central da costa brasileira. In: CONGRESSO SOBRE RESTINGAS BRASILEIRAS, 1984. Rio de Janeiro. Anais..., Rio de Janeiro, UFF, v. 1, p. 35-45.

Frontalini, F. \& Coccioni, R. 2008. Benthic foraminifera for heavy metal pollution monitoring: A case study from the central Adriatic Sea coast of Italy. Estuarine, Coastal and Shelf Science, 76(2): 404-417.

Frontalini, F., Buosi, C., Da Pelo, C., Caccioni, R., Cherchi \& A., Bucci, C. 2009. Benthic foraminifera as bio-indicators of trace element pollution in the heavily contaminated Santa Gilla lagoon (Cagliari, Italy). Marine Pollution Bulletin, 58: 858-877.

Fürsich, F.T. \& Kirkland, J.I. 1986. Biostratinomy and paleoecology of a Cretaceous brackish lagoon. Palaios, 1: 543560.

Hart, A. \& Kaesler, R. 1986. Temporal changes in Holocene lagoonal assemblages of foraminifera from northeastern Yucatan Peninsula, Mexico. Journal of Foraminiferal Research, 16(2): 98-109.

Hayward, B.W., Grenfell, H.R., Nicholson, K., Parker, R., Wilmhurst, J., Horrocks, M., Swales, A. \& Sabaa, A.T. 2004. Foraminiferal record of human impact on intertidal estuarine environments in New Zealand's largest city. Marine Micropaleontology, 53: 37-66.

Horton, B.P., Whittaker, J.E., Thomson, K.H., Hardbattle, M.I.J., Kemp, A., Woodroffe, S.A. \& Wright, M.R. 2005. The development of a modern foraminiferal data set for sea-level reconstructions, Wakatobi Marine National Park, Southeast Sulawesi, Indonesia. Journal of Foraminiferal Research, 35:1-14.

Horton, B.P. \& Murray, J.W. 2007. The roles of elevation and salinity as primary controls on living foraminiferal distributions: Cowpen Marsh, Tees Estuary, UK. Marine Micropaleontology, 63: 169-186.

Jorissen, F.J. 1999. Benthic foraminiferal microhabitats below the sediment-water interface. In: Gupta, B. K. S. (Ed.). Modern Foraminifera. Norwell, Kluwer Academic Publishers, p. 161-179.

Kjerfve, B. 1994. Coastal lagoons. In: Kjerfve, B. (Ed.). Coastal Lagoon Processes. Amsterdam, Elsevier Oceanography Series, p. 1-8.

Labuz, T.A. 2009. Distal washover fans on Świna Gate Sandbar. Institute of Oceanography, University of Gdańsk, Poland, 38: 79-95.

Lamego, A.R. 1945. Ciclo evolutivo das lagoas fluminenses. Rio de Janeiro, Boletim do DNPM, n.118, 48p.

Laslandes, B., Sylvestre, F., Sifeddine, A., Turcq, B., Albuquerque, A.L.S. \& Abrão, J. 2006. Enregistrement de la variabilité hydroclimatique au cours des 6500 dernières années sur le littoral de Cabo Frio (Rio de Janeiro, Brésil). Comptes Rendus Geoscience, 338: 667-675.

Le Cadre, V., Debenay, J-P. \& Lesourd, M. 2003. Low ph effects on Ammonia beccarii test deformation: implications for 
using test deformations as a pollution indicator. Journal of Foraminiferal Research, 33(1): 1-9.

Leorri, E. \& Cearreta, A. 2004. Holocene environmental development of the Bilbao estuary, northern Spain: sequence stratigraphy and foraminiferal interpretation. Marine Micropaleontology, 51: 75-94.

Martin, L., Suguio, K., Flexor, J.M., Dominguez, J.M.L. \& Bittencourt, A.C.S.P. 1996. Quaternary sea-level history and variation in dynamics along the Central Brazilian coast: consequences on coastal plain construction. Anais da Academia Brasileira de Ciências, 68: 303-354.

Martin, L., Dominguez, J.M.L. \& Bittencourt, A.C.S.P. 2003. Fluctuating Holocene sea levels in Eastern and Southeastern Brazil: evidence from multiple fossil and geometric indicators. Journal of Coastal Research, 19(1): 101-124.

Massey, A. C., Gehrels, W. R., Charman, D. J. \& White, S. V. 2006. An intertidal foraminifera-based transfer function for reconstructing Holocene sea-level change in Southwest England. Journal of Foraminiferal Research, 36: 215-232.

Miranda, L.B., Castro, B.M. \& Kjerfve, B. 2002. Princípios de oceanografia física de estuários. São Paulo, Editora da Universidade de São Paulo, 441p.

Morton, R.A., \& Sallenger, A.H.,Jr. 2003. Morphological impacts of extreme storms on sandy beaches and barriers. West Palm Beach, Florida. Journal of Coastal Research, 19(3): 560-573.

Muehe, D. 1984. Evidências de recuo dos cordões litorâneos em direção ao continente no litoral do Rio de Janeiro. In: Lacerda, L. D., Araújo, D. S. D. Cerqueira, R., Turcq, B. (Eds.). Restingas, Origem, Estrutura, Processos. Niterói, CEUFF, p.75-80.

Murray, J. 2006. Applications. In: Murray, J. (Ed.). Ecology and applications of benthic foraminifera. Cambridge, Cambridge University Press, p. 281-319.

Murray, J.W. \& Alve, E. 1999. Natural dissolution of modern shallow water benthic foraminifera: taphonomic effects on the palaecological record. Paleogeography, Paleoclimatology, Paleoecology, 146: 195-209.

Nimer, E. 1979. Climatologia do Brasil. Rio de Janeiro, IBGE, $422 \mathrm{p}$.

Patterson, R.T. \& Fishbein, E. 1989. Re-examination of the statistical methods used to determine the number of point counts needed for micropaleontological quantitative research. Journal of Paleontology, 63: 245-248.

Perrin, P. 1999. Physiography and surface formations of the east fluminense coast, State of Rio de Janeiro, Brazil. In: Knoppers, B., Bidone, E.D., Abraão, J.J. (Eds). Environmental geochemistry of costal lagoon systems, Rio de Janeiro, Brazil. Niterói, Série Geoquímica Ambiental, 6, p. 25-46.

Scott, D.B., Medioli, F.S. \& Schafer, C.T. 2001. Monitoring in coastal environments using foraminifera and thecamoebian indicators. Cambridge, Cambridge University Press, 177p.

Silva, A.L.C. \& Silva, M.A.M. 2010. Caracterização geomorfológica e sedimentar da planície costeira central de Maricá (Rio de Janeiro). In: SIMPÓSIO NACIONAL DE GEOMORFOLOGIA, 8, 2010. Recife, Anais..., Recife, UGB, v. 1, p. 1-15.

Silva, A.L.C., Rodrigues, A.R., Silva, M.A.M. \& Gambôa, L.A.P. 2010. Arquitetura Sedimentar e Evolução Geológica no Quaternário da Planície Costeira Central de Maricá (Rio de Janeiro). In: CONGRESSO BRASILEIRO DE GEOLOGIA, 45, 2010. Belém, Anais..., Belém, SBG, v. 1.

Simões, M.G. \& Torello, F.F. 2003. Modelo de tafofácies para os moluscos bivalves do Grupo Passa Dois (Formações Serra Alta, Teresina e Corumbataí), Permiano Superior, Bacia do Paraná, Brasil. Revista Brasileira de Geociências, 33(4): 371-380.

Stuiver, M. \& Reimer, P.J. 1993. Extended ${ }^{14} \mathrm{C}$ data base and revised Calib 3.014c age calibration program. Radiocarbon, 35(1): 215-230.

Suguio, K., Martin, L., Bittencourt, A.C.S.P., Dominguez, J.M.L. \& Flexor, J.M. 1985. Flutuações do nível relativo do mar durante o Quaternário superior ao longo do litoral brasileiro e suas implicações na sedimentação costeira. Revista Brasileira de Geociências, 15: 273-286.

Turcq, B., Martin, L., Flexor, J.M., Suguio, K., Pierre, C. \& Tasayaco-Ortega, L. 1999. Origin and evolution of the Quaternary costal plain between Guaratiba and Cabo Frio, State of Rio de Janeiro, Brazil. In: Knoppers, B., Bidone, E.D., Abraão, J.J. (Eds). Environmental geochemistry of costal lagoon systems, Rio de Janeiro, Brazil. Niterói, Série Geoquímica Ambiental, 6, p. 25-46.

Vance, D.J., Culver. S.J., Corbett. D.R. \& Buzas, M.A. 2006. Foraminifera in the Albemarle estuarine system, North Carolina: distribution and recent environmental change. Journal of Foraminiferal Research, 36: 15-33.

Walton, W.R. \& Sloan, B. J. 1990. The genus Ammonia Brunnich, 1772: its geographic distribution and morphologic variability. Journal of Foraminiferal Research, 20(2): 128156.

Wilson, B., Miller, K., Thomas, A-L, Cooke, N. \& Ramsingh, R. 2008. Foraminifera in the mangal at the Caroni Swamp, Trinidad: diversity, population structure and relation to sea level. Journal of Foraminiferal Research, 38(2): 127136.

Woodroffre, S.A., Horton, B.P., Larcombe, P. \& Whittaker, J.E. 2005. Intertidal mangrove foraminifera from the central Great Barrier Reef shelf, Australia: implications for sea-level reconstruction. Journal of Foraminiferal Research, 35(3): 259-270.

Manuscrito 502

Editores: Marina B. Soares e Paulo A. Souza. 


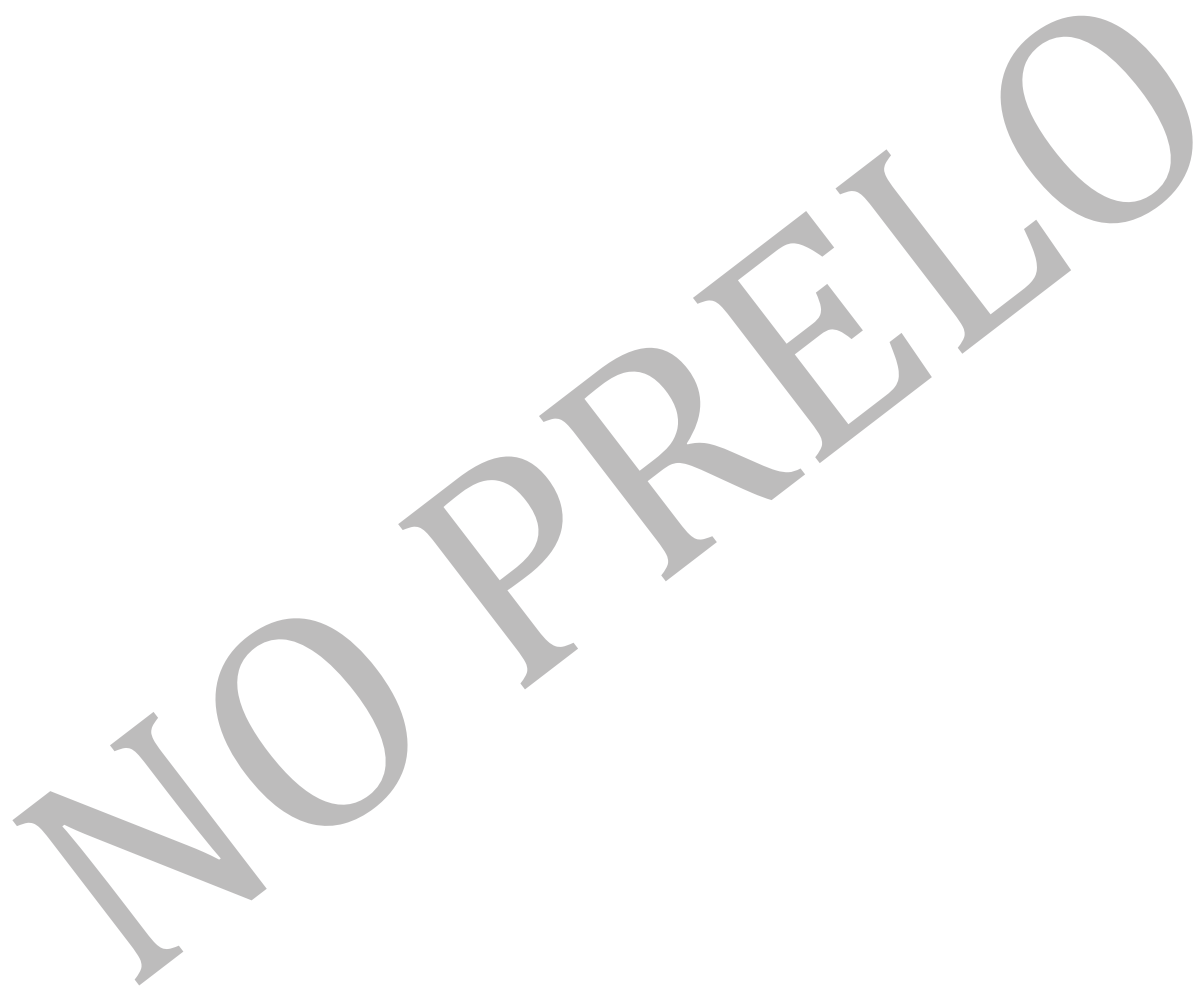

